\title{
Structure and adsorption properties of a
}

\section{porous cooper hexacyanoferrate polymorph}

R. Roque-Malherbe ${ }^{a, *}$, E. Carballo $^{a}$, R. Polanco ${ }^{a}, F$. Lugo $^{a}$ and C. Lozano ${ }^{a}$

a. School of Science, University of Turabo, PO Box 3030, Gurabo, PR, 00778-3030, USA.

b. Chemistry Department, University of Puerto Rico-Mayagüez Campus, Mayagüez, P.R. 006819000, USA.

* Corresponding author: Prof. R. Roque-Malherbe, email: RRoque@suagm.edu and RRoquemalh@aol.com; Phone: 1-787-743-7979 ext. 4260, Fax: ext. 4114. 


\section{ABSTRACT}

The key questions addressed here were: the structure elucidation and the investigation of the adsorption space and framework expansion effect of a $\mathrm{Cu}(\mathrm{II})$ hexacyanoferrate (III) polymorph (labelled $\mathrm{Cu}-\mathrm{PBA}-\mathrm{I})$. The structural analysis was performed with a broad set of characterization methods. Additionally, a low and high pressure carbon dioxide adsorption investigation was performed, assuming, to comprehend the adsorption experiments, that the adsorbent plus the adsorbed phase were a solid solution. We concluded: that the Cu-PBA-I presented the following composition, $\mathrm{K}_{1 / 4} \mathrm{Cu}(\mathrm{II})\left[\mathrm{Fe}(\mathrm{III})(\mathrm{CN})_{6}\right]_{3 / 4} \diamond_{1 / 4} n \mathrm{H}_{2} \mathrm{O}$, exhibited an antiferromagnetic behavior and displayed a thermally stable $I \overline{4} m 2$ space group lattice in the degassed state. Moreover, the low pressure adsorption study allowed the calculation of the micropore volume, $W=0.09 \mathrm{~cm}^{3} / g$ and the isosteric heat of adsorption, $q_{i s o}=19 \mathrm{~kJ} / \mathrm{mol}$; further, the high pressure adsorption data revealed an extremely high adsorption capacity owing to a framework expansion effect. Finally, the DRIFTS spectrum of adsorbed $\mathrm{CO}_{2}$ displayed peaks corresponding to carbon dioxide physically adsorbed and interacting with electron accepting Lewis acid sites. Hence, was produced an excellent adsorbent which combine porosity and anti-ferromagnetism, antagonist properties rarely found together.

Keywords: carbon dioxide, adsorption, Prussian blue analog, antiferromagnetism, gas storage. 


\section{INTRODUCTION}

One essential characteristic of the sustainable development of the present and future Human society involve the economically and environmentally advantageous storage, separation and removal of small gas molecules, as for example: carbon dioxide, methane, ammonia and hydrogen, between others [1]. Particularly, for these purposes $\mathrm{CO}_{2}$ occupies a special position; since their emissions cause global warming; because it influence the balance of received and emitted energy leading to the increase of the earth temperature, stimulating: sea level elevation, the increase in the oceans acidity and the strengthening of tropical storms, between other harmful effects [2].

One of the carbon dioxide emission sources is the burning of fossil fuels for industrial, transportation and other uses, since these processes releases large amounts of $\mathrm{CO}_{2}$ into the atmosphere perturbing carbon steadiness in the earth that has been stable over hundreds of millions of years [3]. Hence, undoubtedly some approaches to reduce $\mathrm{CO}_{2}$ emissions are urgently required to minimize climate change. In this regard, to reduce these emissions hydrogen as a clean fuel for transportation and industrial uses and methane as a car fuel, since it is considerably cleaner than petroleum, has been used [4,5]. In addition, the elimination of $\mathrm{CO}_{2}$ from the chimney of power plants, presently a key source of emissions, is normally achieved by cooling and pressing the exhaust or by contacting the fumes across a fluidized bed of aqueous amine solution, however, both methods are expensive and ineffective [6]. Other methods based on chemisorption of $\mathrm{CO}_{2}$ on oxide surfaces or adsorption within porous silicates, carbons, metal organic frameworks and other adsorbents have been pursued as means for $\mathrm{CO}_{2}$ uptake [3-6]. 
However, the attainment of new adsorbents for carbon dioxide storage is still a vigorous research topic [5]. In this regard, transition metal cyanides [8-21] exhibiting structures assembled with transition metals, attached through the linear cyanide ion, as a consequence of their magnetism [14], physical adsorption [15-19] and other attributes [9-14], are a significant class of materials. In particular, metal hexacyanometalates isostructural to Prussian blue, namely Prussian blue analogs (PBAs), exhibit developed adsorption and magnetic properties between other characteristics $[9,19,20,21]$.

The backbone of the structure of PBAs is the $-M^{\prime}-C \equiv N-M-N \equiv C-M^{\prime}-$ chain. This atomic sequence is straight hence PBAs typically crystallize in the cubic system, specifically, in the $F m \overline{3} m$ space group and in less extent in the $\operatorname{Pm} \overline{3} m[19]$. Even though, some PBAs crystalizes in the tetrahedral, $I \overline{4} m 2$ [10] and $I 4 m m[18]$ space groups. Moreover, if $M^{\prime}=F e(I I I)$, and $M=$ $M(I I)$, the following, $A_{x} M(I I)\left[\mathrm{Fe}(I I I)(C N)_{6}\right]_{z} \diamond_{1-z} n H_{2} \mathrm{O}$, generalized formula has been proposed to describe the stoichiometry of these materials [9], where the symbol, $\diamond$, indicates $[\mathrm{Fe}(\mathrm{III})$ $\left.(\mathrm{CN})_{6}\right]^{\mu-}$ vacancies, generated together with the interstitial cations to produce charge balance in the framework. In this regard, some possible representatives compositions for these materials are [13], $\quad A M(I I)\left[\mathrm{Fe}(I I I)(C N)_{6}\right] \quad(M / F e=1), \quad M(I I)\left[\mathrm{Fe}(I I I)(C N)_{6}\right]_{2 / 3} \diamond_{1 / 3} n H_{2} O(M / F e=3 / 2) \quad$ and $A_{1 / 4} M(I I)\left[\mathrm{Fe}(I I I)(\mathrm{CN})_{6}\right]_{3 / 4} \diamond_{1 / 4} n H_{2} O(M / F e=4 / 3)$, where the voids results to microporous frameworks.

The investigation of carbon dioxide physical adsorption [22] and the analysis of the infrared spectra of adsorbed $\mathrm{CO}_{2}$ [23-25] are outstanding methods for the characterization of the porosity and surface chemistry of porous materials. Hence, the adsorption of this gas is an excellent tool for the investigation of the adsorption space of PBAs and other materials [26-31]. 
For the last years the investigation of PBAs became an expanding research field, specially, when materials with high thermal stability and porosity are produced [32-36]. Thereafter, the main questions investigated here were: the structural elucidation and the study of the adsorption properties and thermal stability of a porous $\mathrm{Cu}$ (II) hexacyanoferrate (III) polymorph (labelled $\mathrm{Cu}-\mathrm{PBA}-\mathrm{I})$ and the synthesis and characterization of the standard $\mathrm{Cu}(\mathrm{II})$ hexacyanoferrate (III) (labelled Cu-PBA) for comparison.

\section{EXPERIMENTAL SECTION}

The consumable chemicals were analytical grade. Water was bi-distilled.

Firstly, the synthesis of the standard $\mathrm{Cu}(\mathrm{II})$ hexacyanoferrate(III) was carried out following the recipes reported in literature [19] to get the sample labelled Cu-PBA. Secondly, the synthesis of the $\mathrm{Cu}$ (II) hexacyanoferrate(III), different to the standard one, took place by mixing 0.025 moles of solid potassium hexacyanoferrate (III) and solutions containing 0.025 moles of $\mathrm{Cu}\left(\mathrm{NO}_{3}\right)_{2}$ in $250 \mathrm{~mL}$ of water, at $70{ }^{\circ} \mathrm{C}$, under constant stirring, next, the formed precipitate was filtered, washed with distilled water and dried at $343 \mathrm{~K}$ for $24 \mathrm{~h}$ to get the sample labelled Cu-PBA-I.

Next, X-Ray diffraction (XRD) profiles were collected (Bruker D8 Advance) using a BraggBrentano vertical goniometer configuration. The angular measurements were made using steps of 0.01 degree. The $\mathrm{X}$-ray radiation source was a ceramic $\mathrm{X}$-ray diffraction $\mathrm{Cu}$ anode tube type KFL C 2K. In addition, a Soller slit was included and a Ni filter was placed prior to the detector. Also, a LynxEye ${ }^{\mathrm{TM}}$ one-dimensional detector was used for X-ray detection. 
Afterwards, the scanning electron microscopy (SEM) images were obtained at $20 \mathrm{kV}$ (JEOL, JSM-6360) for sample grains placed on a carbon tape. At the same time as, elemental chemical analysis was performed using the energy dispersive x-ray analysis (EDAX) included in the SEM. Subsequently, the thermo-gravimetric analysis (TGA) testing process was carried out (TA, Q500). The sample and holder were heated according to a predetermined thermal cycle from 25 to $700{ }^{0} \mathrm{C}$ at a heating rate of $5{ }^{0} \mathrm{C} / \mathrm{min}$ while flowing $100 \mathrm{ml} / \mathrm{min}$ of pure $\mathrm{N}_{2}$ (Praxair, $99.99 \%$ ). The TGA profiles were collected as a $W t . \%$ versus $T\left({ }^{0} \mathrm{C}\right)$ graphic, where $W t . \%=\left(M_{t} / M_{0}\right) x 100$ is the percent -ratio of the sample mass for the thermal treatment $M_{t}$ and the initial mass of the sample $M_{0}$.

Afterward, diffuse reflectance Fourier transform infrared spectrometry (DRIFTS) spectra were gathered (Nicolet iS10). The spectra were collected at a resolution of $4 \mathrm{~cm}^{-1}$ employing 200 scans per sample in a high temperature infrared cell. The hydrated samples spectra were obtained at room temperature under $\mathrm{N}_{2}$ flow at $50 \mathrm{ml} / \mathrm{min}$ rate. To get the spectra of the dehydrated samples it were heated at 473 under a flow of $\mathrm{N}_{2}$ at $50 \mathrm{ml} / \mathrm{min}$ rate for 2 hours. Then, the spectra of the degassed materials were obtained at room temperature, under $\mathrm{N}_{2}$ flow. Similarly, a Raman spectrum was taken with a Renishaw Raman microspectrometer RM2000 system equipped with a Leica microscope using a 20x objective and a charge-coupled device (CCD) detector. Then, the spectrum was obtained with a laser line at $532 \mathrm{~nm}$, generated by a Spectra Physics EXCELSIOR solid state diode laser, in the range of 100-3500 Raman Shift $\left(\mathrm{cm}^{-1}\right)$ with an integration time of 15 s per scan, averaging fifteen scans.

Later, the magnetization curve ( $\mathrm{M}$ versus $\mathrm{H})$ was collected at room temperature $(300 \mathrm{~K})$ in the vibrating sample magnetometer (VSM) (Lakeshore 7400). To perform the test, the powder 
sample was weighted, located on the sample holder and subsequently was generated the ramp from -2.2 to $2.2 \mathrm{~T}$ and backward.

Lastly, carbon dioxide (Praxair, $99.99 \%$ ) adsorption was investigated at $300 \mathrm{~K}$ and pressure up to 1 bar (LP) (Quantachrome AS-1) and at $300 \mathrm{~K}$ and pressure up to $30 \mathrm{bar}$ (HP) (Quantachrome iSorbHP-100), on samples degassed at $423 \mathrm{~K}$ for three hours in high vacuum $\left(10^{-6}\right.$ Torr). The backfilling process was performed using helium (Praxair, $99.99 \%$ ). Furthermore, the DRIFTS spectrum of carbon dioxide adsorbed in the Cu-PBA-I was collected utilizing as background the dehydrated sample at room temperature. After that, a $\mathrm{CO}_{2}$ flow at a rate of $50 \mathrm{ml} / \mathrm{min}$ for three minutes was passed through the dehydrated samples, next, the sample was purged under $\mathrm{N}_{2}$ flow at a rate of $50 \mathrm{ml} / \mathrm{min}$ for one minute, and then a spectrum of the carbon dioxide molecule adsorbed on the $\mathrm{Cu}$-PBA-I adsorption space was obtained at room temperature under $\mathrm{N}_{2}$ flow.

Finally, the curve fitting processes were performed with the analysis and peak separation software PeakFit ${ }^{\circledR}$ (Seasolve Software Inc., Framingham, Massachusetts) based on a least square procedure [37]. The program made possible the calculation of the best fitting parameters in the case of curve fitting. For peak separation the software made possible the calculation of the band parameters, i.e., intensity, peak position and half-band-width using for the spectrum fitting Lorentzian functions.

\section{RESULTS AND DISCUSSION}

\subsection{Structural characterization of the synthesized Cu-PBA-I}

First of all, the powder XRD profiles of the as-synthesized Cu-PBA and Cu-PBA-I were collected and resolved into separate Bragg components using the Pawley powder pattern 
decomposition method, by means of the Bruker AXS TOPAS ${ }^{\circledR}$ powder X-ray diffraction analysis software. The profiles were fitted assuming the $P m \overline{3} m$ space group (SG) for the Cu-PBA (Fig. 1a) [23] and the tetragonal $I \overline{4} m 2$ SG for the Cu-PBA-I (Fig. 1b) respectively. Likewise, in Table 1 are reported the refined parameters. The profile of the $\mathrm{Cu}-\mathrm{PBA}$ and the refined cell parameters (Table 1) agreed with the XRD data previously published [19]; meanwhile, the crystallographic information reported for the Cu-PBA-I, indicated that was produced a different polymorph. Secondly, three SEM images corresponding to the Cu-PBA-I material were collected (Fig. 1a, 1b and 1c). These images exhibited the formation of particles of $60 \mu \mathrm{m}$ shaped by aggregates of $0.5-$ $1 \mu \mathrm{m}$ formed by the $25 \mathrm{~nm}$ Cu-PBA-I crystallites. In addition, EDAX elemental chemical analysis of the Cu-PBA-I was performed (see Fig. 1d). In this regard, the elemental composition was calculated as the average of ten tests similar to those reported in Fig 1d. Thereafter, the average concentration plus the calculated standard deviation $(\sigma)$ expressed in molar per-cent was calculated and reported in Table 2 .

Subsequently, to further understand the properties of both synthesized materials, the thermogravimetric analysis (TGA) method was used (Fig. 3). The TGA results made possible the following inferences: water was released up to $200{ }^{0} \mathrm{C}$, for both materials; in this sense, the derivative of the TG profiles evidenced, for the $\mathrm{Cu}-\mathrm{PBA}$, demonstrated that the liberation of adsorbed water took place, in two steps, the first at $60{ }^{\circ} \mathrm{C}$ and the second at $150{ }^{\circ} \mathrm{C}$, meanwhile, for the PBA-I a broad peak that was resolved in two components, i.e., one at $80{ }^{\circ} \mathrm{C}$ and the other at $110{ }^{\circ} \mathrm{C}$ was observed (see Fig. 3e). Finally, at $300{ }^{\circ} \mathrm{C}$ for the $\mathrm{Cu}$-PBA and $210{ }^{\circ} \mathrm{C}$ for the $\mathrm{Cu}$ PBA-I the decomposition of both materials was evidenced [18]. Hence, the TGA profiles demonstrated the release of "zeolitic" water from the Cu-PBA-I in the course of heating, a behavior similar to those exhibited by the Cu-PBA [19]. 
Next, in Fig. 4 are shown the DRIFTS spectra of the as-synthesized (Fig. 4a and 4b) and dehydrated (Fig. 4c and 4d) Cu-PBA-I. The main IR active vibrations observed in the 1500-2500 $\mathrm{cm}^{-1}$ range are the absorption bands corresponding to the $\mathrm{OH}$ bending at $1610 \mathrm{~cm}^{-1}$ and the $\mathrm{CN}$ stretching modes [33]. Since, CN bands are the main vibrations in Prussian blue analogues; then, a curve fitting processes, to analyze the band components was made (Fig. 4b). In this regard, in Table 3 are reported the calculated peak position $\left(\mathrm{x}_{\mathrm{i}}\right)$, half-band-width $(\sigma)$ and intensity $(\mathrm{A})$ of the peaks related to the $\mathrm{CN}$ vibration modes. The peaks located ca. $2174 \mathrm{~cm}^{-1}$ and ca. $2103 \mathrm{~cm}^{-1}$ in the hydrated (Fig. 4b) and dehydrated (Fig. 4d) Cu-PBA-1 were associated to the $\mathrm{CN}$ stretching vibration, $\mathrm{Cu}(I I)-N \equiv C-F e(I I I)$ [32]. Since, $\mathrm{Cu}-\mathrm{PBA}-\mathrm{I}$ is a rather pure material, as is evidenced in the XRD pattern (Fig. 1b); hence, the existence of two peaks; could be only related to the PBA structure; for the reason that, the $C u(I I)-N \equiv C-F e(I I I)$ chains are located on two different sub-lattices, $\alpha$ and $\beta$ in the tetragonal $I \overline{4} m 2$ SG body centered cubic framework, (Fig. 5a). For example, Fe (III) is located in the vertices ( $\alpha$ sub-lattice) and the center ( $\beta$ sub-lattice) of the tetragonal cell [9]. Furthermore, the peak located on $2010 \mathrm{~cm}^{-1}$ was assigned to the CN group $(-N \equiv C-F e(I I I)-C \equiv N-C u(I I)-)$ not bonded at the $\mathrm{N}$ termination, while the band located on ca. $1945 \mathrm{~cm}^{-1}$ for the dehydrated Cu-PBA-II, can be accredited to a minute new phase formed in the course heating [34]. Moreover, the bands present in the $3000-3800 \mathrm{~cm}^{-1}$ range were related to the hydroxyl functionalities, in this regard, the narrow peak $3660 \mathrm{~cm}^{-1}$, was assigned to the stretching vibrations of the $\mathrm{OH}$ groups corresponding to linked water, while the vibrations related to the hydrogen bonded water molecules were evidenced in the broad peak located in the range between 3000-3600 $\mathrm{cm}^{-1}$ [35]. Both bands almost disappeared after dehydration (Fig. 4b). Thereafter, in Fig. 5 and Table 4 are reported the position and the assignment of the Raman bands in the low frequency region. In this frequency span, the typical bands related to iron and 
cooper coordinated to carbon and nitrogen, are, two stretching modes, i.e., $v(\mathrm{FeC})$ and $v(\mathrm{CuN})$ together with four bending ones, namely, $\delta(\mathrm{FeCN}), \delta(\mathrm{NFeN}), \delta(\mathrm{CuCN}$ and $\delta(\mathrm{NCuN})$ [8]. In the case of cubic PBAs six bands must be observed, even though, for tetragonal PBAs two additional bands are detected, because of their lower symmetry [36]. In this regard, since we observed eight peaks (Table 4), hence the Raman data confirmed the assumed the tetragonal $I \overline{4} m 2$ SG for the Cu-PBA-f.

Afterwards, the magnetization curve of the Cu-PBA-I is reported in Fig. 6. This curve indicated an antiferromagnetic behavior; because, it shows saturation, hysteresis and a very small magnetization. We could explain this antiferromagnetic effect as related to the existence of two different $C u(I I)-N \equiv C-F e(I I I)$ chains located on two different sub-lattices, $\alpha$ and $\beta$ (Fig. 7a). Each chain is ferromagnetic since $\mathrm{Cu}(\mathrm{II})$ has six electrons in $\mathrm{t}_{2 \mathrm{~g}}$ orbitals and three electrons in the $e_{g}$ orbitals, where the unpaired electron is placed in a $e_{g}$ orbital; meanwhile, $\mathrm{Fe}$ (III) has five electrons in $t_{2 g}$ orbitals; therefore, the unpaired electron is placed in a $t_{2 g}$ orbital; hence, since each chain is ferromagnetic; but in the present; based on the obtained results (Fig. 6) their magnetization are oppositely-directed.

Now, the elemental composition (Table 2), the TGA profiles (Fig, 3) and the PBAs compositions reported in literature $\quad[13], \quad$ i.e., $\quad A M(I I)\left[\mathrm{Fe}(I I I)(C N)_{6}\right](M / F e=1)$, $M(I I)\left[\mathrm{Fe}(I I I)(C N)_{6}\right]_{2 / 3} \diamond_{1 / 3} n H_{2} O(M / F e=3 / 2)$ and $A_{1 / 4} M(I I)\left[\mathrm{Fe}(I I I)(C N)_{6}\right]_{3 / 4} \diamond_{1 / 4} n H_{2} O(M / F e=4 / 3)$, allowed us to propose the following chemical formula: $K_{1 / 4} \mathrm{Cu}(\mathrm{II})\left[\mathrm{Fe}(\mathrm{III})(\mathrm{CN})_{6}\right]_{3 / 4} \diamond_{1 / 4} n \mathrm{H}_{2} \mathrm{O}$, for the produced Cu-PBA-I. Subsequently, using the experimentally obtained crystallographic information (Table 1), the proposed chemical formula, the atomic positions reported in Table 5, Wyckoff sites and occupancy factors reported in the International Tables for Crystallography 
[40] and crystallographic data found in literature [41], was produced with the software PowderCell-2.4 [42] the unit cell representation for the framework of the Cu-PBA-I (see Fig. 7). Finally, the XRD diffraction pattern of the Cu-PBA-I was fitted with the Rietveld method by means of the Bruker AXS TOPAS ${ }^{\circledR}$ software package using the atomic positions, Wyckoff sites and occupancy factors previously applied to generate the Cu-PBA-I framework (Fig. 78). The fitting process was performed while the atomic position, occupancy factors and isotropic thermal factors for the cations and anisotropic thermal factors for the oxygen ions were kept fixed, and the cell parameters refined. The calculated cell parameters were, within the experimental error, the same reported in Table 1. These results validated the proposed framework.

\subsection{Carbon dioxide adsorption on $\mathrm{Cu}-\mathrm{PBA}-\mathrm{I}$}

To get the $\mathrm{CO}_{2}$ adsorption isotherm, the tested material was degassed in vacuum at $423 \mathrm{~K}$ for 3 hours. Subsequently, adsorption data at $300 \mathrm{~K}$ was collected, for, $P$, the adsorption equilibrium pressure up to $1 \mathrm{Bar}$ (low pressure range), that is, $0.00002<P / P_{0}<0.015$, where, $P_{0}$, is the vapor pressure of carbon dioxide at $300 \mathrm{~K}$. Next, to characterize the adsorption space of the $\mathrm{Cu}-$ PBA-I was used the Dubinin-Radushkevitch (D-R) adsorption isotherm equation:

$$
\ln \left(n_{a}\right)=\ln \left(N_{a}^{0}\right)-\left(\frac{R T}{E}\right)^{2} \ln \left(\frac{P_{0}}{P}\right)^{2}
$$

Wherein, $n_{a}$, is the amount adsorbed, $P / P_{0}$, is the relative pressure, $E$, is the characteristic energy of adsorption, and, $N_{a}^{0}$, is the maximum amount adsorbed in the micropore volume at low pressure (LP) . Subsequently, the fitting of the adsorption isothem of carbon dioxide at $300 \mathrm{~K}$, up to 1 bar, on the $\mathrm{Cu}-\mathrm{PBA}-\mathrm{I}$ and the $\mathrm{Cu}-\mathrm{PBA}$, for comparisson, to the D-R equation (Fig. 8) allowed the calculation (see Table 6) of, $N_{a}^{0}$ and, $E$, plus, $W_{0}$, the micropore volume, calculated using the 
Gurtvich rule, $W_{0}=N_{a}^{0} V_{\mathrm{CO}_{2}}$ (where, $V_{\mathrm{CO}_{2}}=48.3 \mathrm{~cm}^{3} / \mathrm{mol}$ is the carbon dioxide molar volume) and, $q_{\text {iso }}$, the isosteric heat of adsorption, computed using the following methodology [42]: $q_{\text {iso }}(\theta)=-\Delta G(\theta)+E F(T, \theta), \quad \Delta G(\theta)=R T \ln \left(P / P_{0}\right) \quad$ and $\quad F(T, \theta)=(\alpha T / 2)(\ln [1 / \theta])^{-\frac{1}{2}}$ where, $\theta=n_{a} / N_{a} ; \alpha=-d \ln N_{a} / d T, E=\Delta G(1 / e)$, for $\theta=1 / e$, for, $e \approx 2.71828183$. Hence, for $\theta=1 / e \approx 0.37$ was possible to get the following equation, $q_{\text {iso }}(0.37)=-\Delta G(0.37)+E F(T, 0.37)=E[F(T, 0.37)-1]$, where, $F(T, 0.37) \approx 2.16$, consequently, on this ground, was obtained the relation: $q_{\text {iso }}(0.37)=1.16 E[43]$.

The magnitude of the micropore volume $\left(W_{0}\right)$ implied that the Cu-PBA-I PBA is a microporous crystalline material. Furthermore, the value measured for the isosteric heat of adsorption was sufficiently small to infer the absence of strong acid sites in the adsorption space [44].

Similarly, in Fig. 9 are exhibited the high pressure carbon dioxide adsorption-desorption isotherms in terms of the surface excess amount carbon dioxide adsorption isotherm, $n_{a}(\mathrm{mmol} / \mathrm{g})$ (Fig. 9a) and the pore volume $\left(\mathrm{cm}^{3} / g\right.$ ) (Fig. 9b). Where, the excess adsorption amount was measured with the volumetric method using the following equation: $n_{a}=n_{t}-\rho_{g} V_{g}$, in which, $n_{t}$, was the total amount adsorbed, $\rho_{g}$, the adsorbate density and, $V_{g}$, the dead volume that include the pore volume of the adsorbent [45]. To measure, $V_{g}$, was used a reference gas, specifically, He, for which the amount adsorbed, $n_{a}$, is considered zero i.e., $n_{a}=n_{t}-\rho_{g} V_{g}=0$, accordingly, $V_{g}=n_{t} / \rho_{g}$, where, $\rho_{g}$, is the density of He [46]. Meanwhile the pore volume was calculated with the expression, $W=n_{t} V_{\mathrm{CO}_{2}}$, where, $V_{\mathrm{CO}_{2}} \mathrm{~cm}^{3} / \mathrm{mol}$ was the carbon dioxide molar volume. Subsequently, the adsorption isotherms reported in Fig. 9 indicated that as a consequence of the process the adsorption space was not saturated, conversely, the amount adsorbed continuously 
increased. This fact is possible because an adsorbent in the course of the adsorption processes could experience deformation, that is, adsorption can produce the expansion of the adsorbent structure $[47,48]$.

Now, to work out the adsorption process an important assumption was made, specifically, the adsorbent plus the adsorbed phase was considered as a solid solution, i.e., the adsorbateadsorbent system $(a A)$; thereafter, the fundamental thermodynamic equation, within the frame of the solution thermodynamic approach; for this system is given by [49]:

$$
d U_{a A}=T d S_{a A}-P d V_{a A}+\mu_{a} d n^{a}+\mu_{A} d m
$$

Where, $U_{a A}, S_{a A}$ and $V_{a A}$ are the internal energy, entropy and volume of the system $a A$, while $\mu_{a}$ ( in $J / m o l$ ) and $\mu_{A}$ (in $J / K g$ ) are the chemical potentials of the adsorbed and solid phases in the solution and, $n^{a}$, and $m$ the amount of moles of adsorbate and the adsorbent mass in the system $a A$. Hence:

$$
U_{a A}=T S_{a A}-P V_{a A}+\mu_{a} n^{a}+\mu_{A} m
$$

On this ground, is possible to write the internal energy per unit mass of adsorbent as follows:

$$
\bar{U}_{a A}=T \bar{S}_{a A}-P \bar{V}_{a A}+\mu_{a} n_{a}+\mu_{A}
$$

Where, $n_{a}=n^{a} / m$. Now the internal energy for the unit mass of empty adsorbent is given by:

$$
\bar{U}_{A}=T \bar{S}_{A}-P \bar{V}_{A}+\mu_{A}^{0}
$$

Therefore:

$$
U_{a}=\bar{U}_{a A}-\bar{U}_{A}=T S_{a}-P V_{a}+\mu_{a} n_{a}+\Phi
$$

Where, $\quad S_{a}=\bar{S}_{a A}-\bar{S}_{A}, \quad V_{a}=\bar{V}_{a A}-\bar{V}_{A} \quad$ and $\Phi=\mu_{A}-\mu_{A}^{0}$. Likewise, the fundamental thermodynamic equation for the adsorbed phase is given by: 


$$
d U_{a}=T d S_{a}-P d V_{a}+\mu_{a} d n_{a}+d \Phi
$$

Therefore, since the Grand potential is defined as: $\Omega=U-T S-\mu n$, hence:

$$
\begin{gathered}
\Omega_{a}=U_{a}-T S_{a}-\mu_{a} n_{a}-\Phi \\
d \Omega_{a}=d U_{a}-T d S_{a}-S_{a} d T-d \mu_{a} n_{a}-\mu_{a} d n-d \Phi
\end{gathered}
$$

Consequently, substituting equation " 5 " in equation " 6 " we get:

$$
d \Omega_{a}=-P d V_{a}-S_{a} d T-n_{a} d \mu_{a}
$$

Now, in equilibrium: $d \mu_{a}=d \mu_{g}=R T \ln f$, where $f$, is the fugacity of the adsorbate, thereafter:

$$
d \Omega_{a}=-P d V_{a}-S_{a} d T-n_{a} R T \ln f=d \Phi
$$

But since, $\Omega_{a}=\Phi$, then, for $T=$ const:

$$
\Phi=R T \int_{0}^{f} n_{a} d(\ln f)-V_{a} P
$$

In the frame of the osmotic theory of adsorption [50], $\Phi=\Pi W$, hence:

$$
\Pi W=R T \int_{0}^{f} n_{a} d(\ln f)-V_{a} P
$$

Where, $W$, is the micropore volume of the adsorbent and, $\Pi=P^{0}-P$, is the osmotic pressure where $P^{0}$, is a pressure that can compress the adsorbate and produce the same effect created by an adsorption field, i.e., an amount, $n_{a}$, of molecules [22]. Subsequently, in order to operate with equation "9", the fugacity of carbon dioxide must be calculated. In this regard, this parameter was computed by using the following expression [51]:

$$
\ln f=\ln P+\left[b-\frac{a}{R T}\right]\left(\frac{P}{R T}\right)
$$

Where, $a$ and $b$ are the van der Waals parameters for carbon dioxide, specifically, $a=36.58\left[\left(\mathrm{~m}^{3} / \mathrm{mol}\right)^{2} \mathrm{~Pa}\right]$ and $b=42.9\left[\mathrm{~m}^{3} / \mathrm{mol}\right]$. 
Accordingly, in Fig. 10 is shown the $\Pi$ versus P plot, calculated with equations "9" and "10". This figure shows a maximum in the osmotic pressure versus pressure plot, fact indicating that a pressure-responsive framework opening sorption event, took place due to a structural transformation in the adsorbent framework induced by the guest molecules [52, 53].

\subsection{DRIFTS study of carbon dioxide adsorption on Cu-PBA-I}

In Figs. 11 are reported the DRIFTS spectra of the dehydrated Cu-PBA-I (Fig 11a) and the same sample during $\mathrm{CO}_{2}$ adsorption (Fig. 11b). Subsequently, this spectrum was fitted with GaussianLorentzian functions (Fig. 12c). Next, the fitting parameters, namely, the peak positions, $x_{i}$, peak full width at half maximum , $\Delta x_{i}$, and the peak area, $A_{i}$, were calculated with the peak separation software PeakFit ${ }^{\circledR}$, in the course of the fitting with Gaussian-Lorentzian functions of the carbon dioxide DRIFTS spectrum (see Table 7).

Since the free carbon dioxide molecule belongs to the $D_{\infty h}$ point group symmetry, four primary vibration modes [13], namely, the symmetric stretching, $v_{1}$, at $1338 \mathrm{~cm}^{-1}$ the doubly degenerate bending vibration, $v_{2 a}$ and $v_{2 b}$ at $667 \mathrm{~cm}^{-1}$, and the asymmetric stretching vibration $v_{3}$ at 2349 $\mathrm{cm}^{-1}$ can be observed.

The study of adsorbed $\mathrm{CO}_{2}$ with IR spectroscopy [23] is normally focused on the range from, 2250 to $2400 \mathrm{~cm}^{-1}$, that is, the range where is observed the asymmetric stretching vibration, $v_{3}$; given that, this vibrational mode of the carbon dioxide molecule is to some extent disturbed from the equivalent position for the gas phase during adsorption [24]. In this regard, in the spectrum reported in Fig. 7c, the band detected at $2338 \mathrm{~cm}^{-1}$ (Table 7), was the result of the physical adsorption of the carbon dioxide molecule [25]. Further, the bands located on $2321 \mathrm{~cm}^{-1}$ was assigned to a combination band [23]. Moreover, there is another band observed at $2348 \mathrm{~cm}^{-1}$, that 
should correspond to the adsorption of carbon dioxide on an electron accepting Lewis acid site forming the following adducts: $\mathrm{Cu}^{2+} \cdot \bullet \bullet O=C=O$ [54].

\section{Conclusions}

A polymorph of $\mathrm{Cu}$ (II) hexacyanoferrate (III) (Cu-PBA-I) and the standard $\mathrm{Cu}$ (II) hexacyanoferrate (III) (Cu-PBA), were synthesized. The key questions addressed in the reported research were the: structure elucidation, investigation of the adsorption space, framework expansion effect in the course of adsorption and magnetic properties of the produced $\mathrm{Cu}$ (II) hexacyanoferrate (III) polymorph (labelled Cu-PBA-I). To answer these questions, these materials were thoroughly investigated with a group of characterization methods, specifically, Xray diffraction (XRD), scanning electron microscopy (SEM), energy dispersive x-ray analysis (EDAX), thermo-gravimetric analysis (TGA), diffuse reflectance Fourier transform infrared spectrometry (DRIFTS), Raman spectrometry (RS), and magnetic measurements. Additionally, low and high pressure carbon dioxide adsorption isotherms were collected, supposing, to understand the adsorption experiment, that the adsorbent plus the adsorbed phase were a solid solution. The inferences made were, the Cu-PBA-I exhibited the following composition, $K_{1 / 4} \mathrm{Cu}(\mathrm{II})\left[\mathrm{Fe}(\mathrm{III})(\mathrm{CN})_{6}\right]_{3 / 4} \diamond_{1 / 4} n \mathrm{H}_{2} \mathrm{O}$; showed an antiferromagnetic behavior at room temperature and displayed a thermally stable $I \overline{4} m 2$ space group lattice in the degassed at $423 \mathrm{~K}$ state. Moreover, the low pressure adsorption study made possible the calculation of the micropore volume, $W=0.09 \mathrm{~cm}^{3} / g$ and isosteric heat of adsorption, $q_{i s o}=19 \mathrm{~kJ} / \mathrm{mol}$; further, the high pressure adsorption isotherms revealed that a pressure-responsive framework opening sorption event, took place due to a structural transformation in the adsorbent framework induced by the 
guest molecules, producing an extremely high adsorption capacity owing to the framework expansion effect. Additionally, the DRIFTS spectrum of adsorbed $\mathrm{CO}_{2}$ displayed peaks corresponding to $\mathrm{CO}_{2}$ physically adsorbed and forming the following adducts, $\mathrm{Cu}^{2+} \bullet \bullet \bullet \mathrm{O}=\mathrm{C}=\mathrm{O}$, that is carbon dioxide adsorbed on an electron accepting Lewis acid site. Hence is possible to conclude that the produced Cu-PBA-I is an excellent adsorbent for carbon dioxide storage and other small molecules which amalgamate porosity and anti-ferromagnetism, antagonist properties rarely found concurrently.

\section{Acknowledgments.}

The authors R.R.M., C.L., F.L. and R.P, acknowledges the financial support provided by the US DoE through the Massey Chair project and recognize the support of the NSF under the project CHE-0959334. We, as well, recognize the collaboration provided by Dr. P. Fierro, who collected the Raman spectrum and the magnetization curve. 


\section{References}

[1] S. Bourrelly, P. L. Llewellyn, C. Serre, F. Millange, T., Loiseauand, G. and Ferey, J. Am. Chem. Soc. 127(2005) 13519

[2] R. K. Pachauri, A. Reisinger (Eds.) IPCC 2007. Climate Change 2007: Synthesis Report; IPCC: Geneva, Switzerland, 2008.

[3] J-R.Li, Y. Mab, M.C. McCarthyb, J. Sculleya, J. Yub, H-K. Jeongb, P.B. Balbuena , H-C. Zhoua, , Coord. Chem. Rev. 255 (2011) 1791

[4] F. Furukawa and Yaghi, O.M. J. Am. Chem. Soc., 131 (2009) 8875

[5] J. Liu, P.K. Hallapally, P.B. McGrail, D.R. Brown and J. Liu, Chem. Soc. Rev., 41 (2012) 2308

[6] J. Johnson, Chem. Eng. News, 82 (2004) 36

[7] A.R. Millward and O.M. Yaghi, J. Am. Chem. Soc., 127 (2005) 17998

[8] A.P. Baioni, M. Vidotti, P.A. Fiorito, E.A., Ponzioand S.I. Cordoba de Torresi, Langmuir 23 (2007) 6796

[9] M. Verdaguer and G. Girolami, Magnetism: Molecules to Materials V. In Miller J. S., Drillon, M. WILEY-VCH Verlag GmbH \& Co. KGaA, Weinheim, (2004) pp. 284

[10] M. Okubo, D. Asakura, Y. Mizuno, J-D. Kim, T. Mizokawa, T. Kudo, I.J. and Honma, Phys. Chem. Lett. 1 (2010) 2063

[11] J. Balmaseda, E. Reguera, A. Gomez, J. Roque, C. Vazquez, M. Autie, On the Microporous J. Phys. Chem. B 107 (2003) 11360.

[12] R. Roque-Malherbe, C. Lozano, R. Polanco, F. Marquez, F. Lugo, A. HernandezMaldonado and J.N. Primera-Pedrozo, J. Sol. State Chem. 184 (2011) 1236 
[13] N.R. de Taconi, K. Rajeshwar and R.. Lezna, Chem. Mater. 15 (2003) 3046

[14] J. Zhang snd A. Lachgar, J. Amer. Chem. Soc. 129 (2007) 250

[15] S. Natesakhawat, J.T. Culp, C. Matranga and B. Bockrath, J. Phys. Chem. C, 111 (2007) 1055

[16] S.S.R. Kaye, H.J. Choi, J.R. Long, J. Am. Chem. Soc. 130 (2008) 16921.

[17] K. Sumida, D.L. Rogow, J.A. Mason, T.M. McDonald, E.D. Bloch, Z.R. Herm, T-H. Bae, and J.R. Long, Chem. Rev. 112 (2012) 724

[18] L. Reguera, C.P. Krap, J. Balmaseda and E. Reguera, J. Phys. Chem. C 112 (2008) 15893

[19] J. Jimenez-Gallegos, J. Rodriguez-Hernandez, H. Yee-Madeira, E. Reguera, J. Phys. Chem. C $114(2010) 5043$

[20] D. Ghoshal, A.K. Ghosh, T. K. Maji, J. Ribas, G. Mostafa, E. Zangrando and N.. Chaudhuri, Inorganica Chimica Acta, 359 (2006) 2593-602

[21] K. L. Gurunatha, G. Mostafa, D. Ghoshal, and T K. Maji, Crystal Growth \& Design, 10 (2010) 2483-2489

[22] R. Roque-Malherbe, Adsorption and Diffusion of Gases in Nanoporous Materials, CRC Press-Taylor \& Francis, Boca Raton, FL, USA, 2007.

[23] F.X. Llabres i Xamena and A. Zecchina, Phys. Chem. Chem. Phys., 4 (2002) 1978

[24] H. Knozinger and S.J. Huber, Chem. Soc., Faraday Trans., 94 (1998) 2047.

[25] B. Bonelli, B. Civalleri, B. Fubini, P. Ugliengo, C. Otero Arean and E. Garrone, J. Phys. Chem. B 104 (2000) 10978

[26] R. Roque-Malherbe, O.N.C. Uwakweh, C. Lozano, R. Polanco, A. Hernandez-Maldonado, P. Fierro, F. Lugo and J. N. Primera-Pedrozo, J. Phys. Chem. C 115 (2011) 15555

[27] M.M. Dubinin, Prog. Surf. Memb. Sci., 9 (1975) 1 
[28] J.A. Dunne, M. Rao, S. Sircar, R.J. Gorte and A.L. Myers, Langmuir 12 (1996) 5896.

[29] Z. Bacsik, R. Atluri, A. Garcia-Bennett and N. Hedin, Langmuir 26 (2004) 10013.

[30] A. Rios, C. Rivera, G. Garcia, C. Lozano, P. Fierro, L. Fuentes-Cobas and R. RoqueMalherbe, R. J. Mater. Sci. \& Eng. A 2 (2012) 284

[31] R. Roque-Malherbe, The Physical Chemistry of Materials: Energy and Environmental Applications; CRC Press: Boca Raton, Florida, 2010.

[32] P. Bhatt, N. Thakur, M.D. Mukadam, S.S. Meene and S.M. Yusuf, J. Phys. Chem. C. 117 (2013) 2676

[33] O. Sato, T. Iyoda, A. Fujishima and K. Hashimoto, Science 272 (1996) 704

[34] R. Martinez-Garcia, M. Knobel and E. Reguera, J. Phys. Chem. B 110 (2006) 7296

[35] D.F. Mullica, D. B. Tippin and E.L. Sappenfield, J. Coord. Chem. 24 (1991) 83.

[36] K.W. Chapman, P.J. Chupas and C.J.; Kepert, J. Am. Chem. Soc. 128 (2006) 7009

[37] N.R. Draper, Smith, H. Applied Regression Analysis (3rd edition), John Wiley \& Sons, New York, 1998.

[38] J. M. D. Coey, M. Venkatesan and H. Xu, Functional Metal Oxides: New Science and Novel Applications, Edited by S. B. Ogale, T. V. Venkatesan, and M. G. Blamire, Wiley-VCH Verlag, New York, 2013, p. 3.

[39] T. Hahn, (Ed.), International Tables for Crystallography (fifth edition), The International Union of Crystallography, Springer, Volume A, 2005.

[40] E. J. M. Vertelman, E. Macallini, D. Gournis, P. Rudolf, T. Bakas, J. Luzon, R. Broer, A. Pugzlys, T.T. A. Lummen, P. H. M. van Loosdrecht and P.van Koningsbruggen, J. Chem. Mater. 18 (2006) 1951 
[41] W. Kraus and G. Nolze, PowderCell-2.4, Federal Institute for Materials Research and Testing, Rudower Chaussee 5 (Berlin, Germany, 2000).

[42] B.P. Bering, M.M. Dubinin and V.V. Serpinskii, J. Coll. Int. Sci. 38 (1972) 185.

[43] R. Roque-Malherbe, R. Polanco and F. Marquez-Linares, J. Phys. Chem. C 114 (2010,) 17773.

[44] R. Roque-Malherbe, Mic. Mes. Mat. 41 (2000) 227.

[45] Y. He and N.A. Seaton, Langmuir 21 (2005) 8297

[46] S. Gumma and O. Talu, Langmuir 26 (2010) 17013

[47] V.A.Tvardoskiy, Sorbent deformation. The Netherland: Elsevier; 2006.

[48] A. Boutin, F-X. Coudert, M-A. Springuel-Huet, A.V. Neimark, G. Ferey and A.H. Fuchs, J. Phys. Chem. C $114(2010) 22237$.

[49] R. Roque-Malherbe, J. Thermal Anal. 32 (1987) 1361

[50] V.P. Bering and V.V. ; Serpinskii, Izv. Akad. Nauk SSSR, ser. xim. (1974) 2427.

[51] C. W. David J. Chem. Education 2004, 81, 1653

[52] A.V. Neimark, F.X. Coudert, C. Triguero, A. Boutin and A.H Fuchs, Langmuir 27 (2011) 4734.

[53] T. K.; Maji and S. Kitagawa, Pure and Applied Chemistry 79 (2007) 2155.

[54] P.L. Llewellyn, S. Bourrelly, C. Serre, A. Vimont, M. Daturi, L. Hamon, G. De Weireld, JS. Chang, D-H; Hong, Y.K. Hwang, S. Jhung and G. Ferey, Langmuir 24 (2008) 7245. 


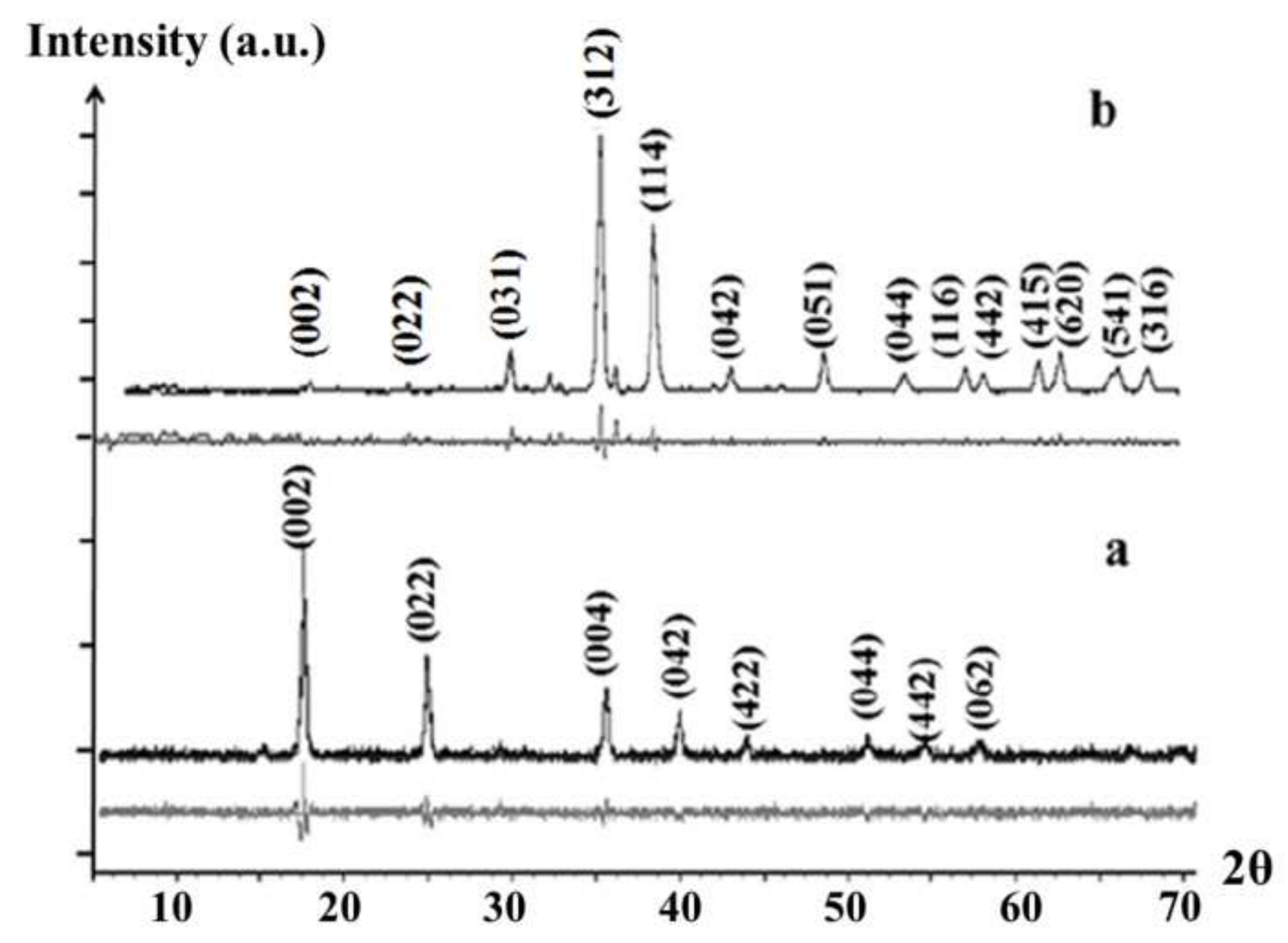



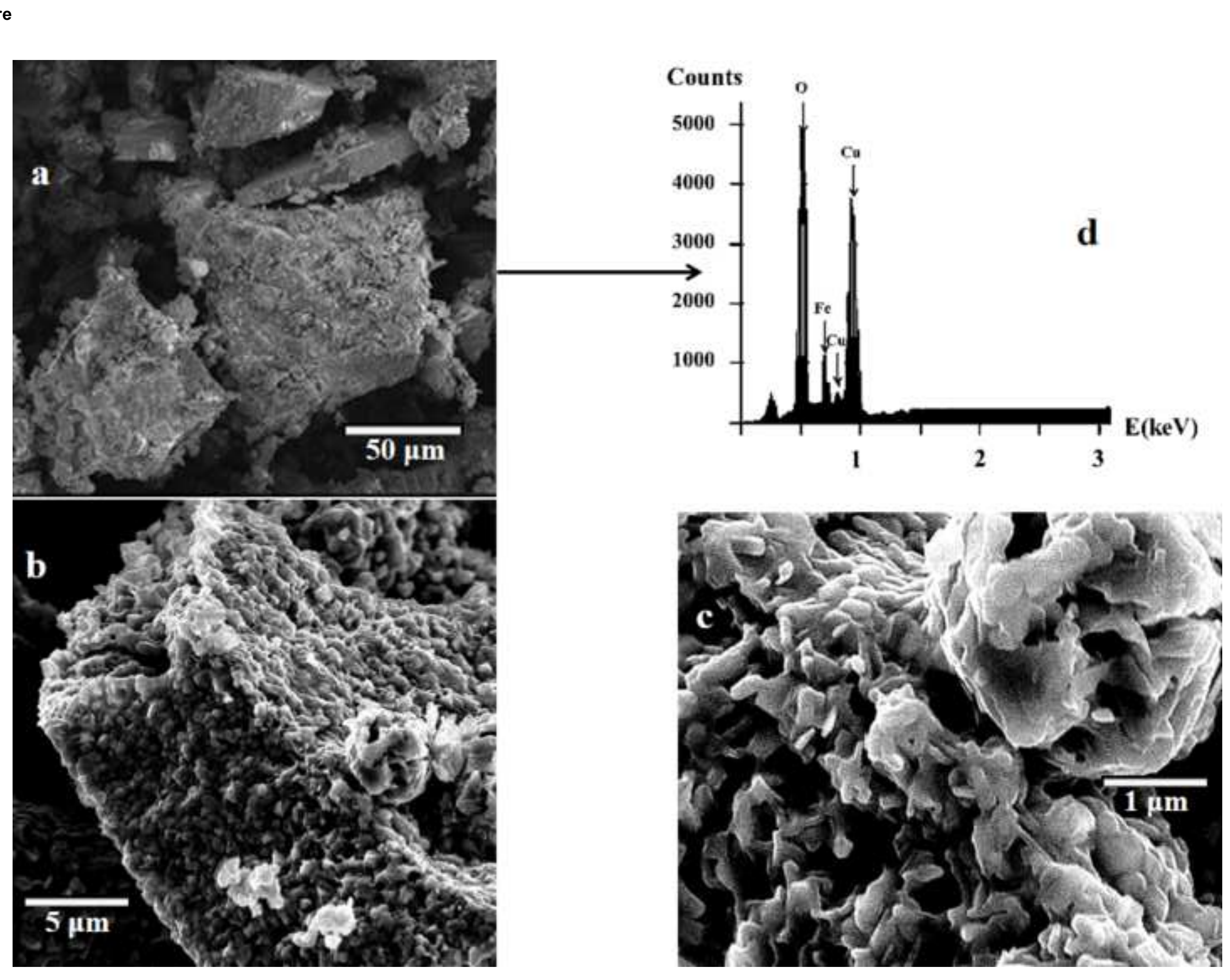
Absorbance
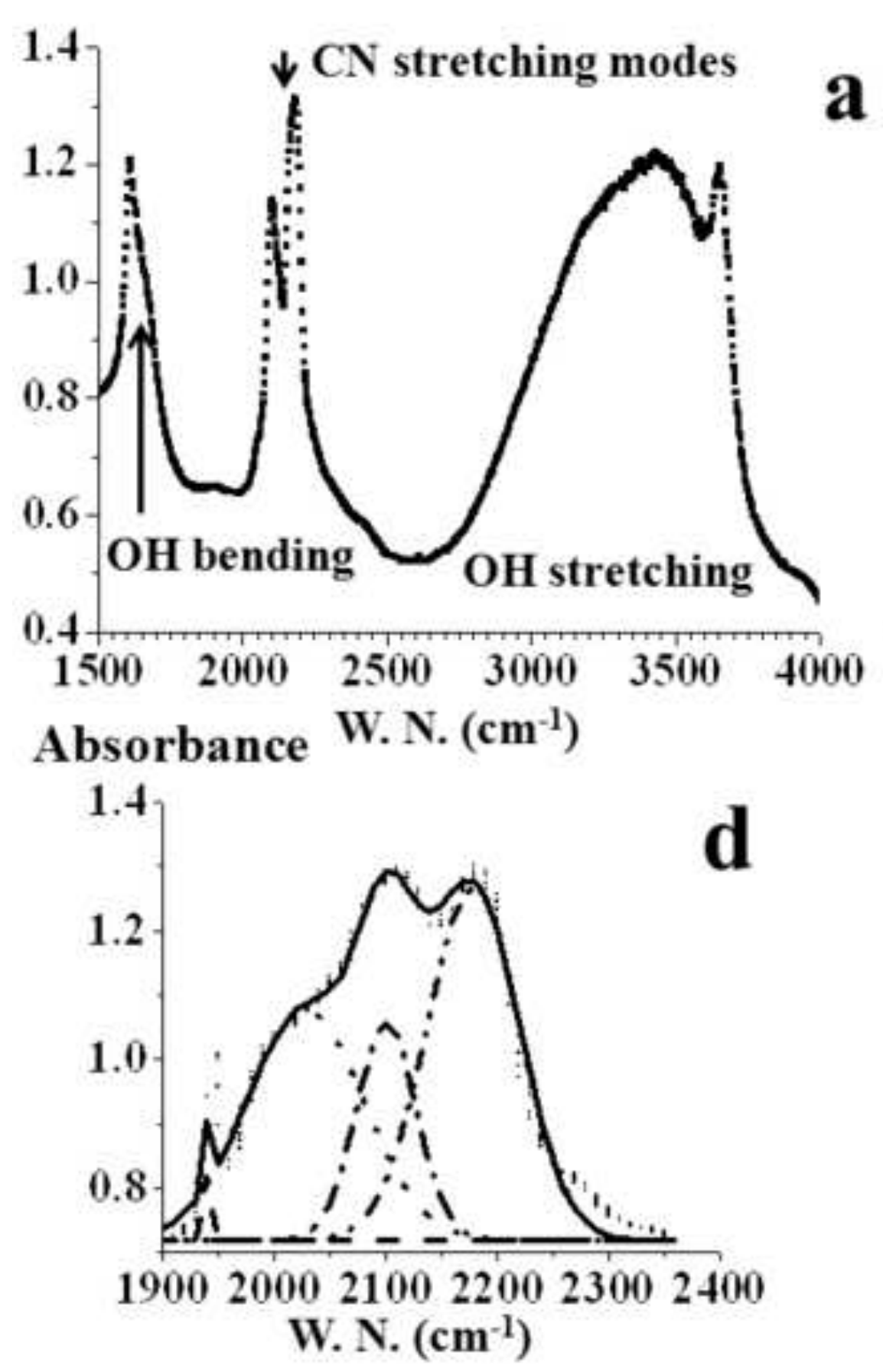

\section{Absorbance}
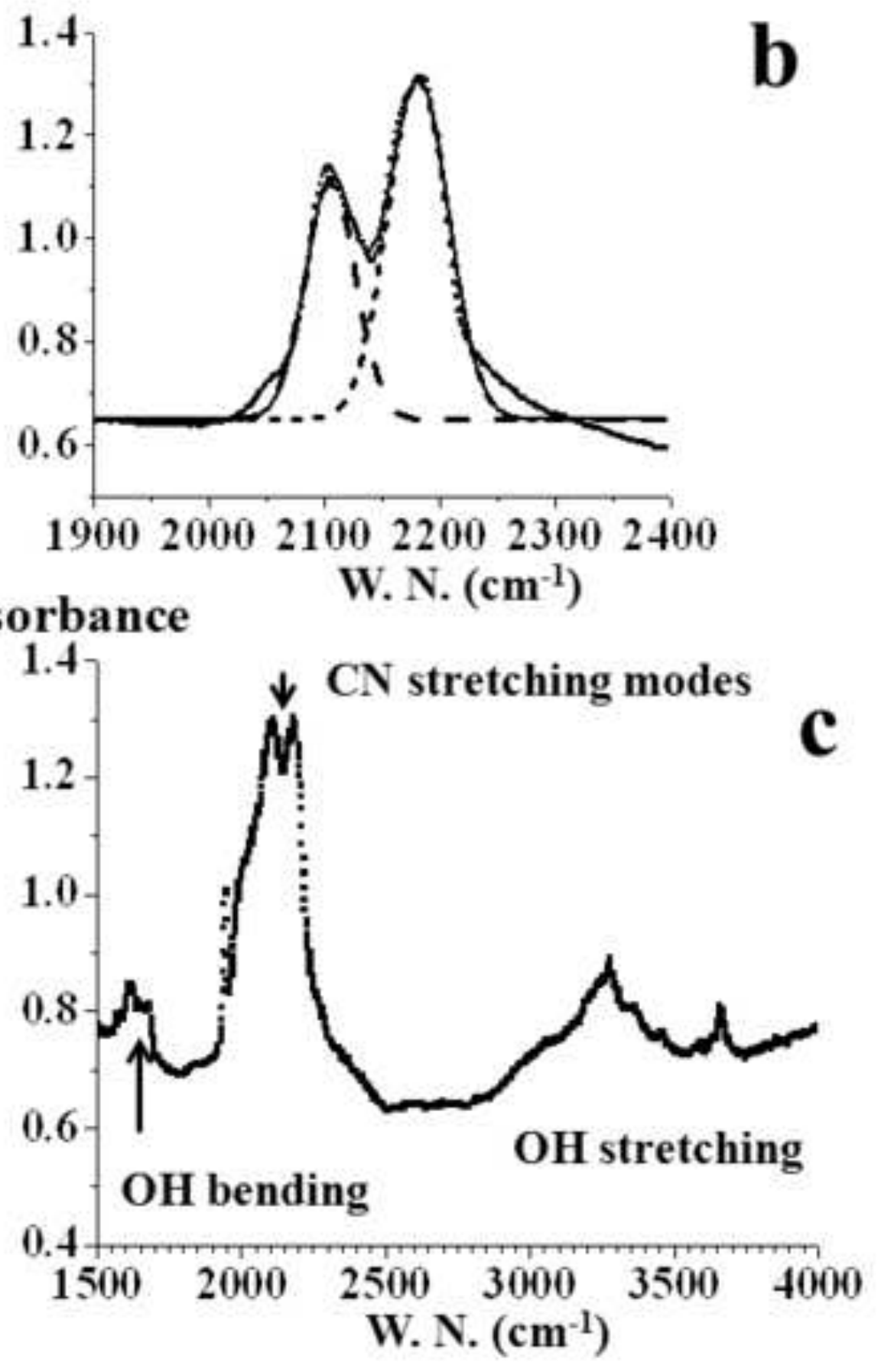


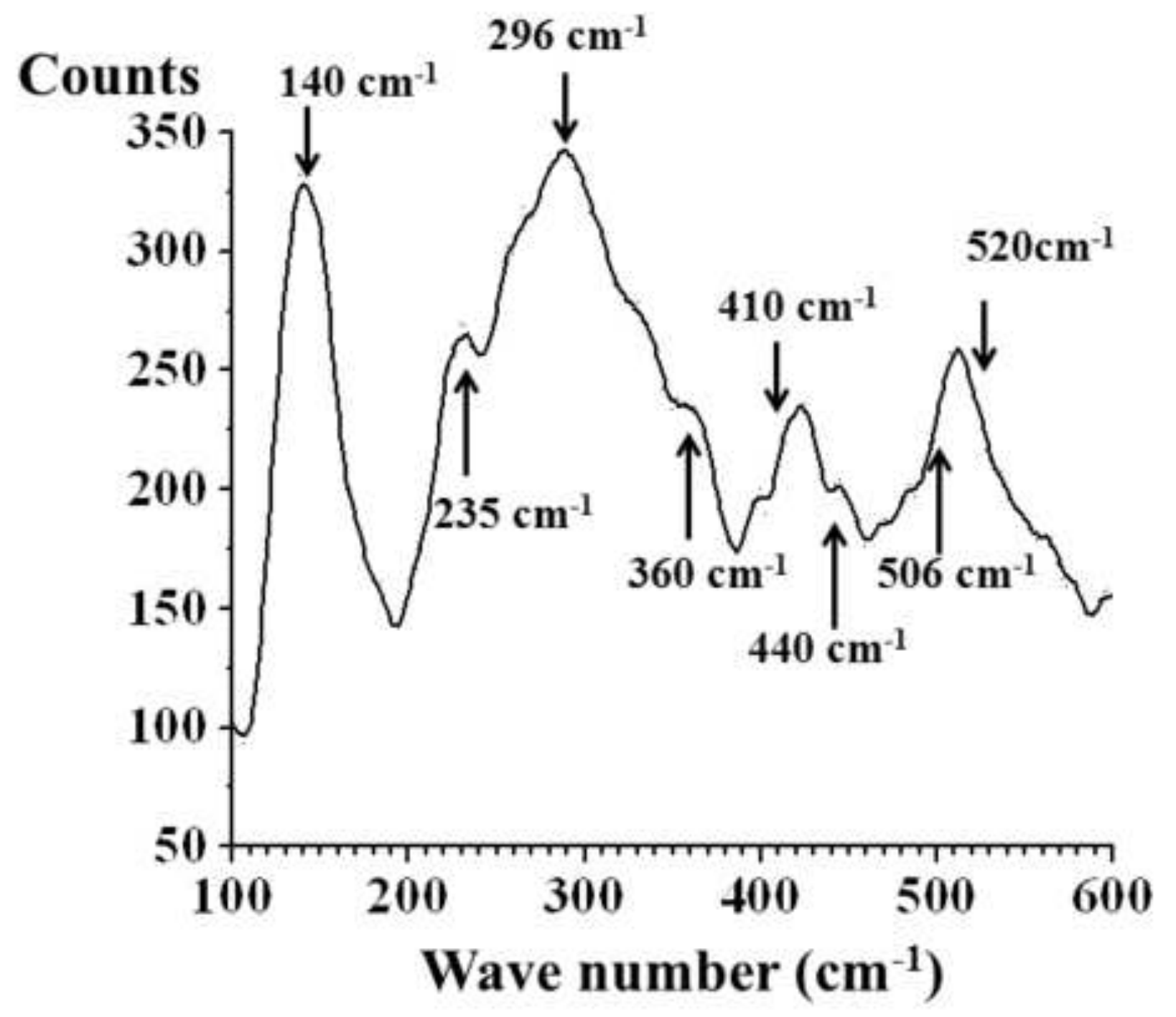




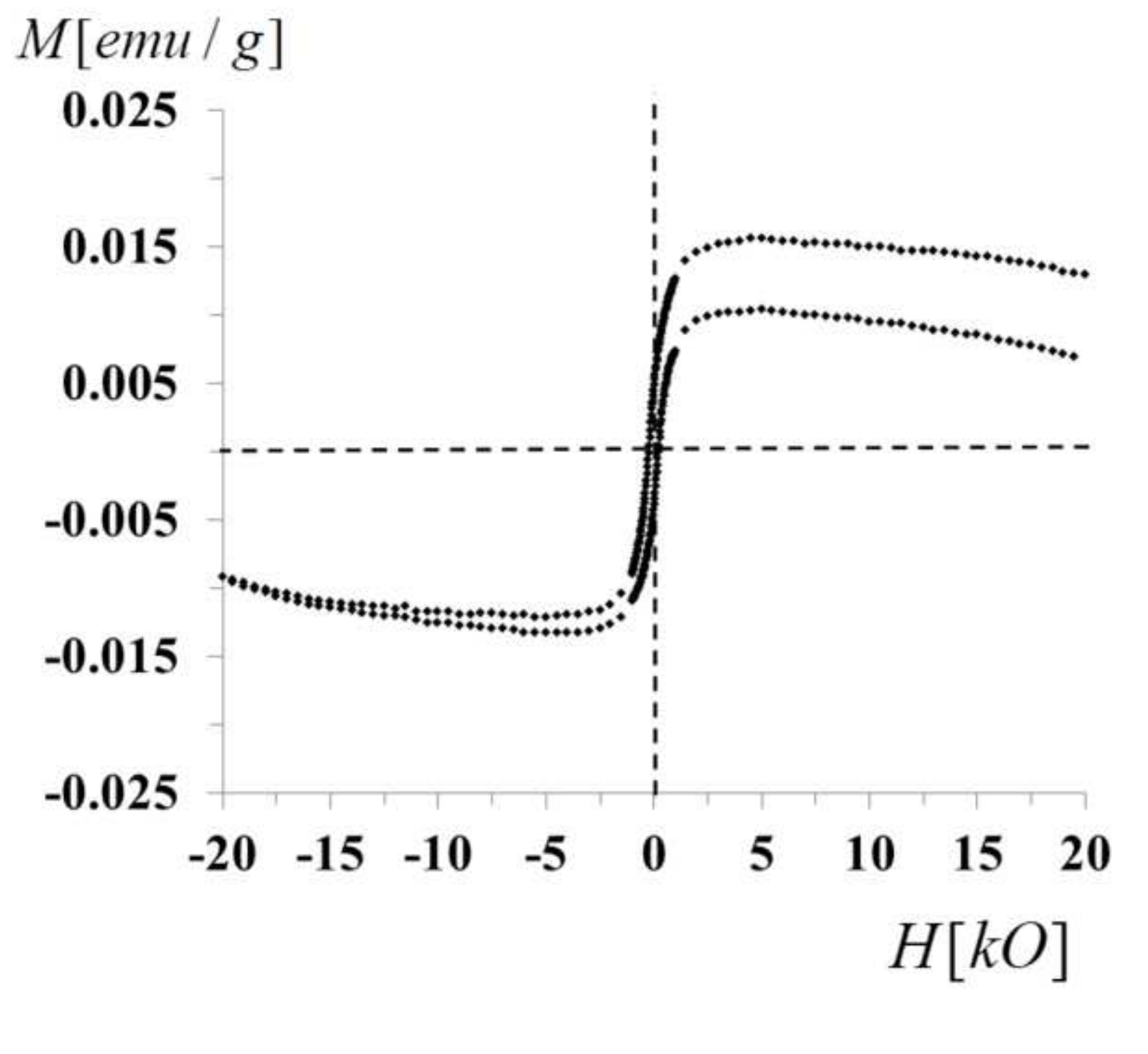

$M[e т u / g]$

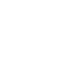

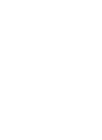

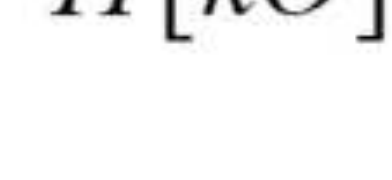



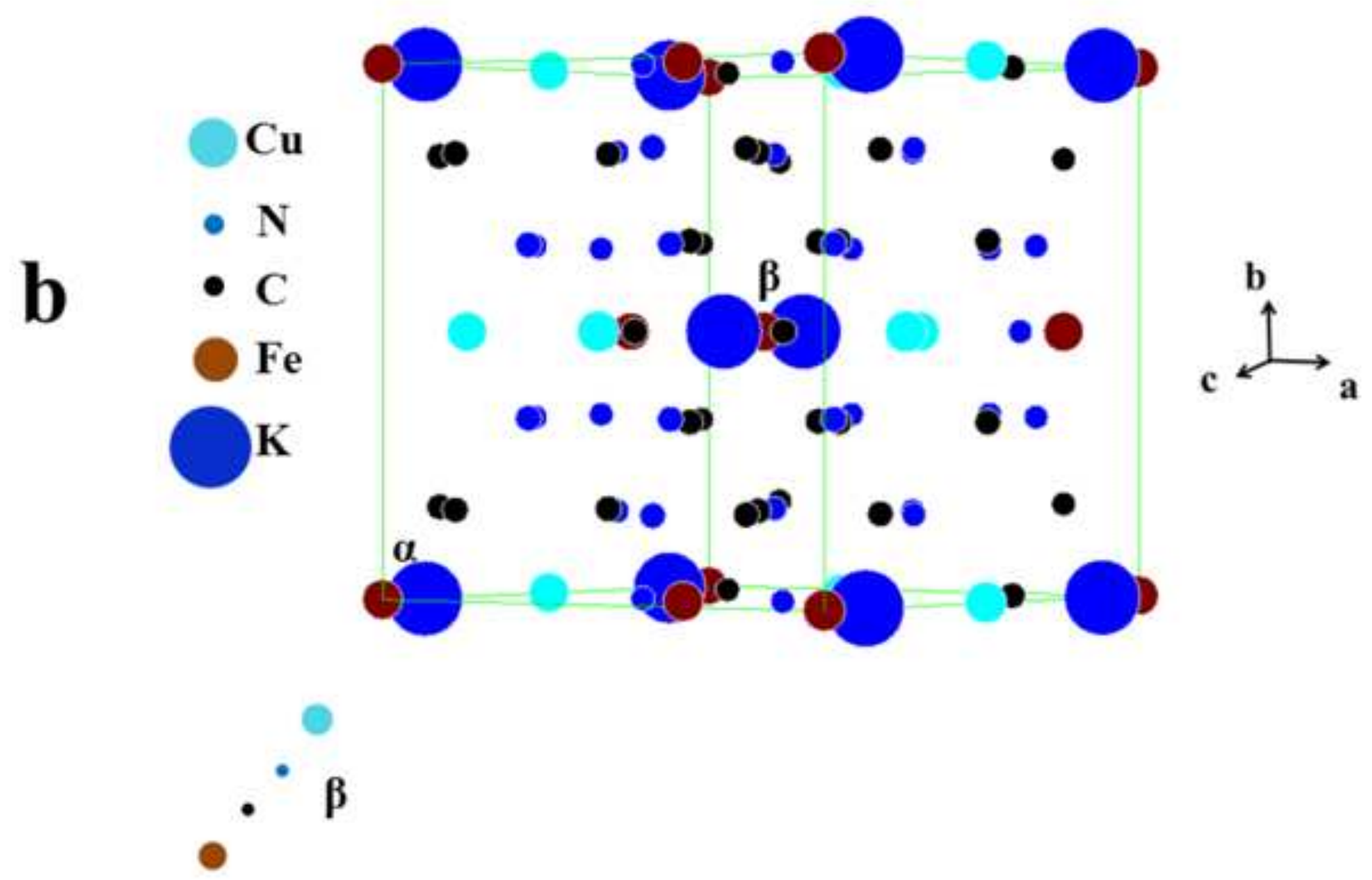

$\mathrm{Fe}(I I I)-\mathrm{C} \equiv \mathrm{N}-\mathrm{Cu}(I I)$

a

$\mathrm{Fe}(I I I)-\mathrm{C} \equiv \mathrm{N}-\mathrm{Cu}($ II $)$ 


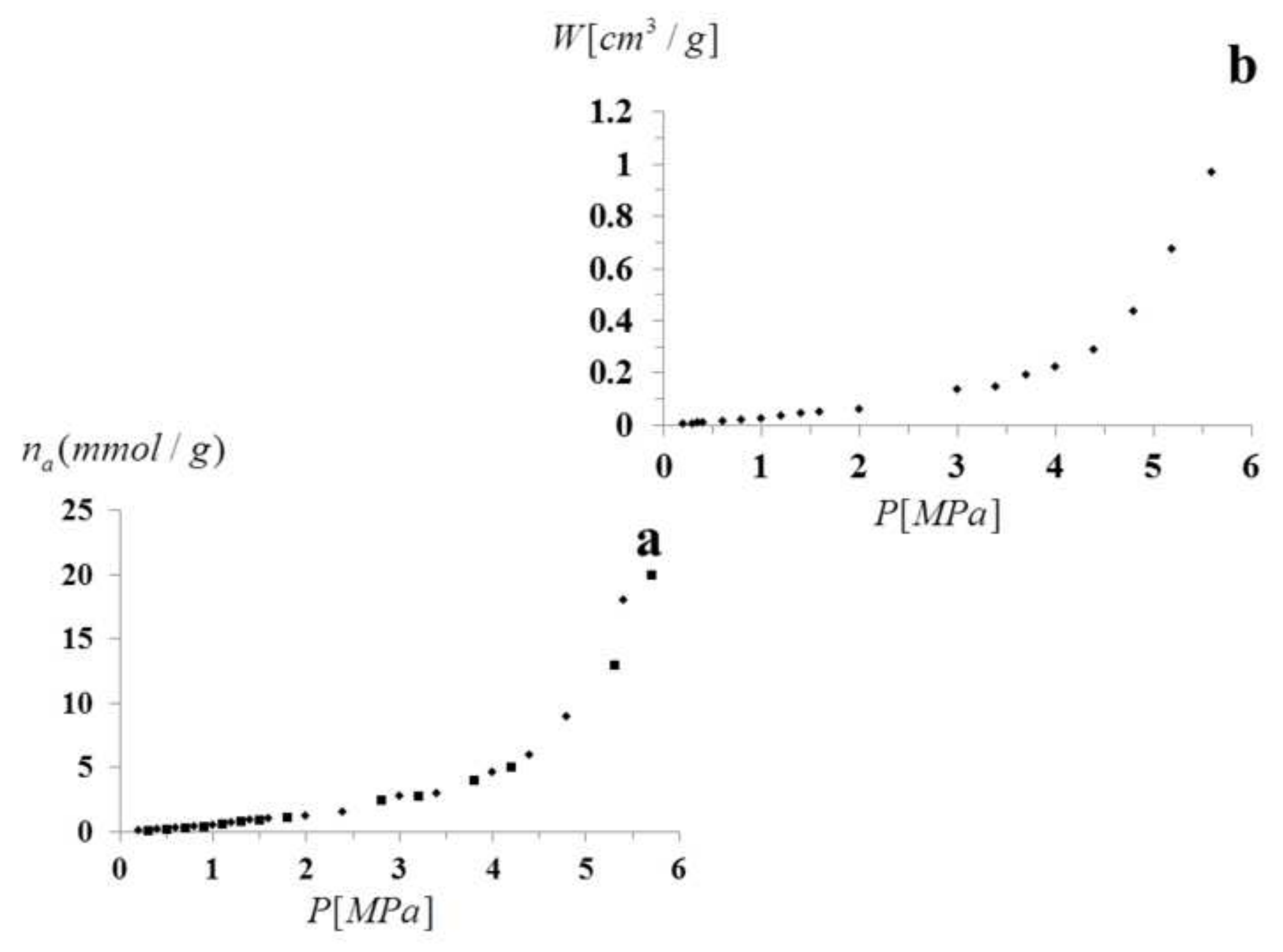

$n_{a}(\mathrm{mmol} / \mathrm{g})$ b

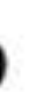

$$
W\left[\mathrm{~cm}^{3} / \mathrm{g}\right]
$$

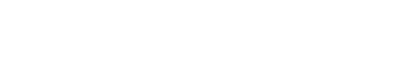

.

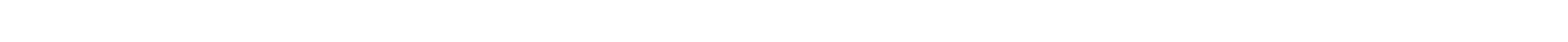

\section{.}

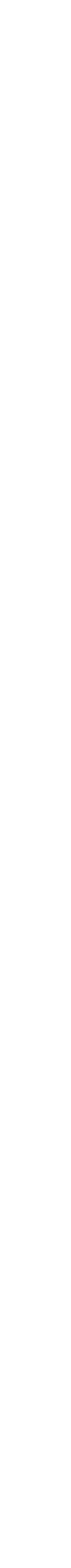


$\Pi[M P a]$

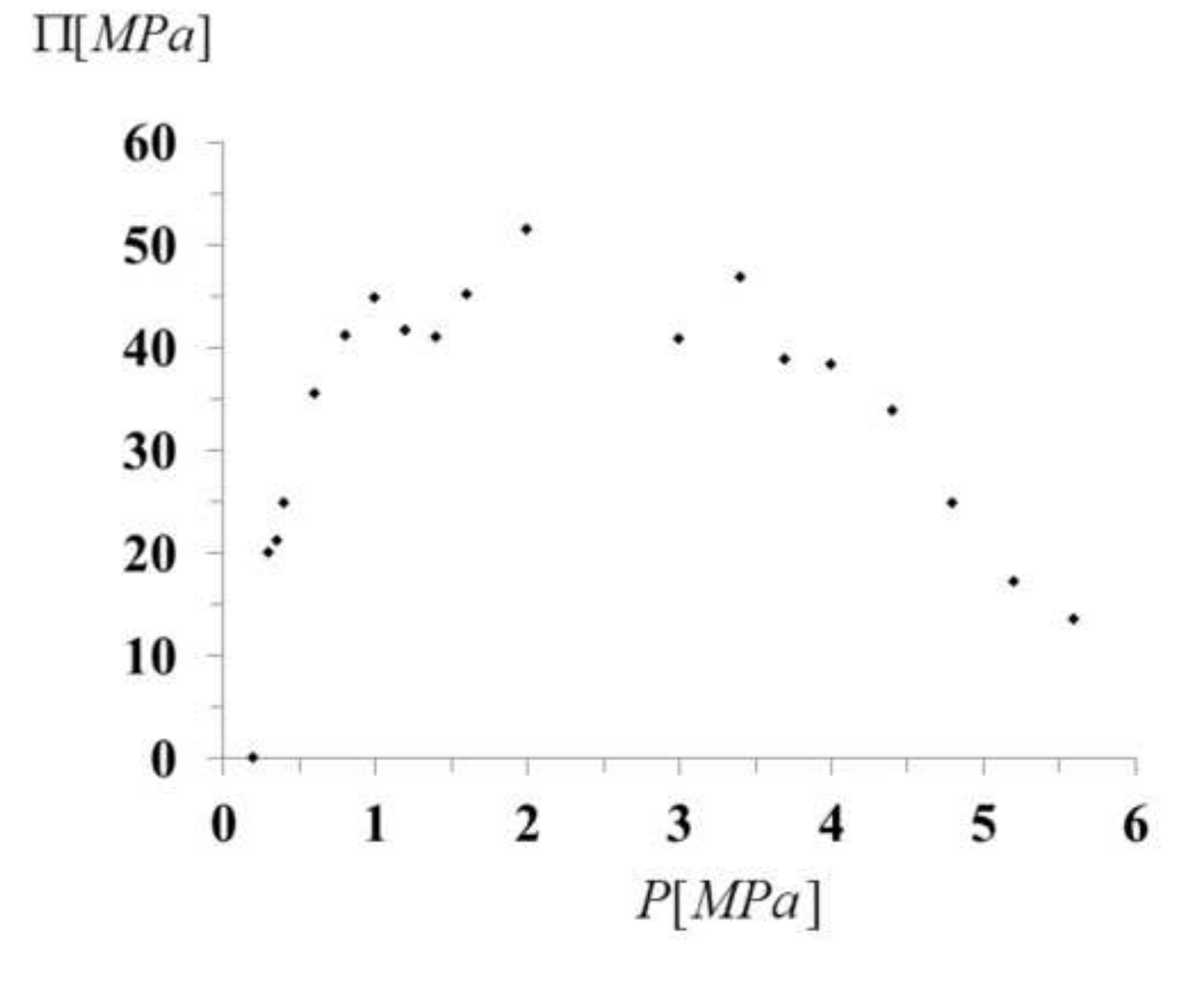

(1)
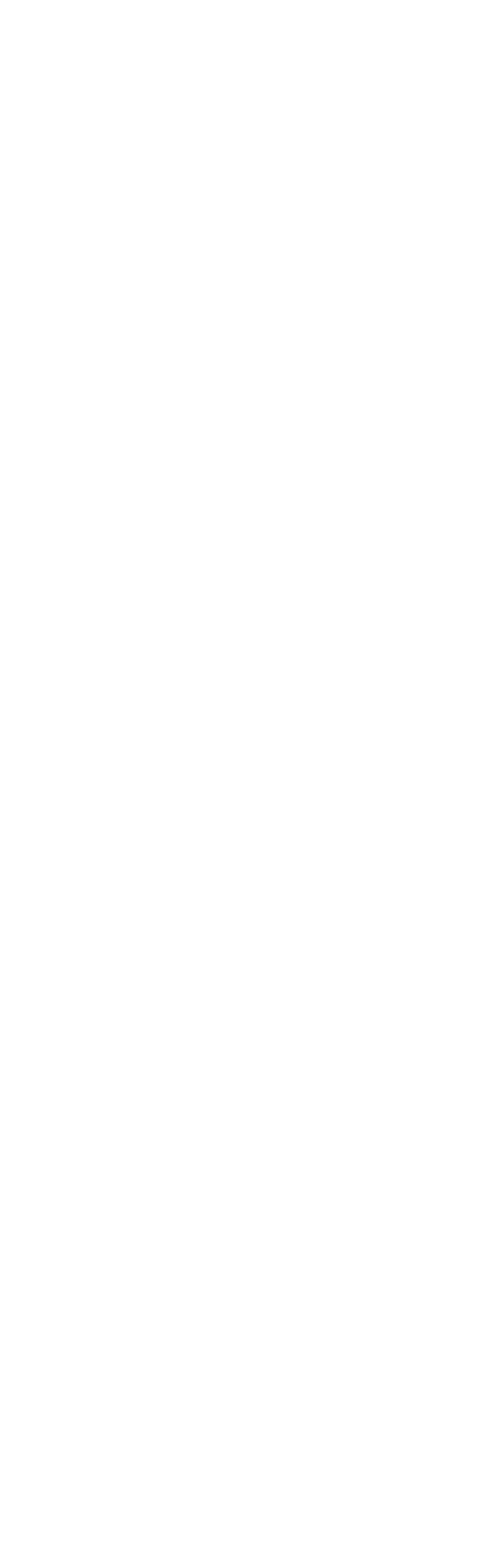


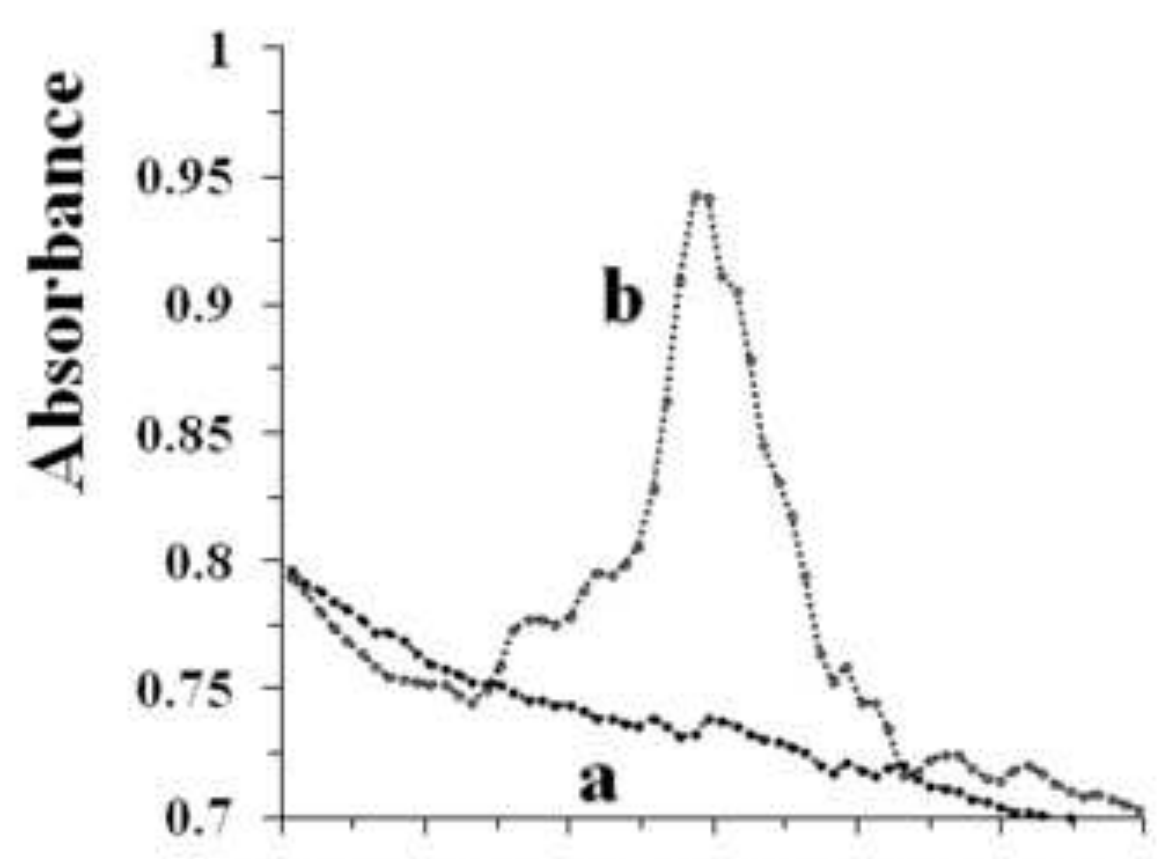

$22802300 \quad 2320 \quad 2340 \quad 2360 \quad 2380 \quad 2400$ Wave number $\left(\mathrm{cm}^{-1}\right)$

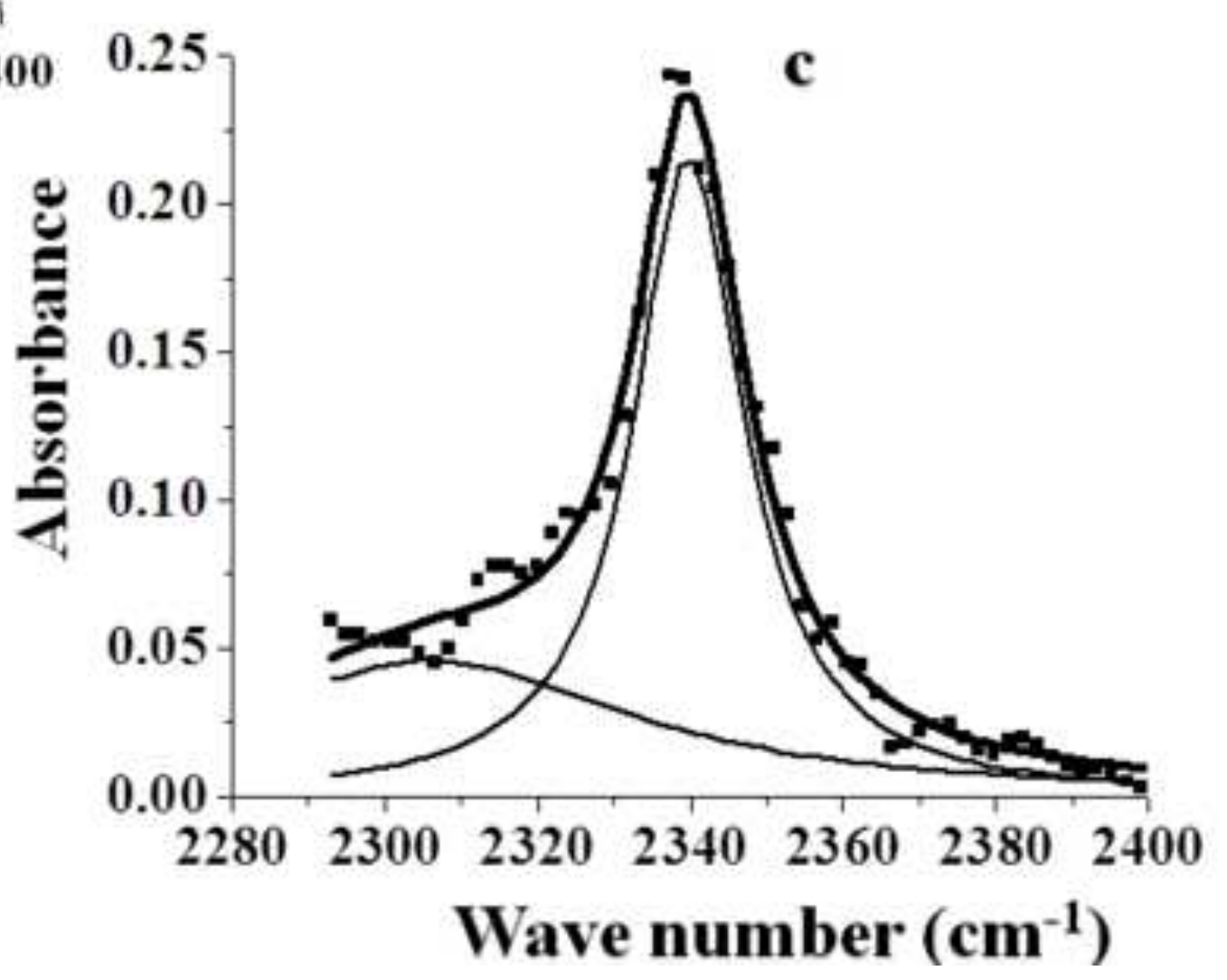




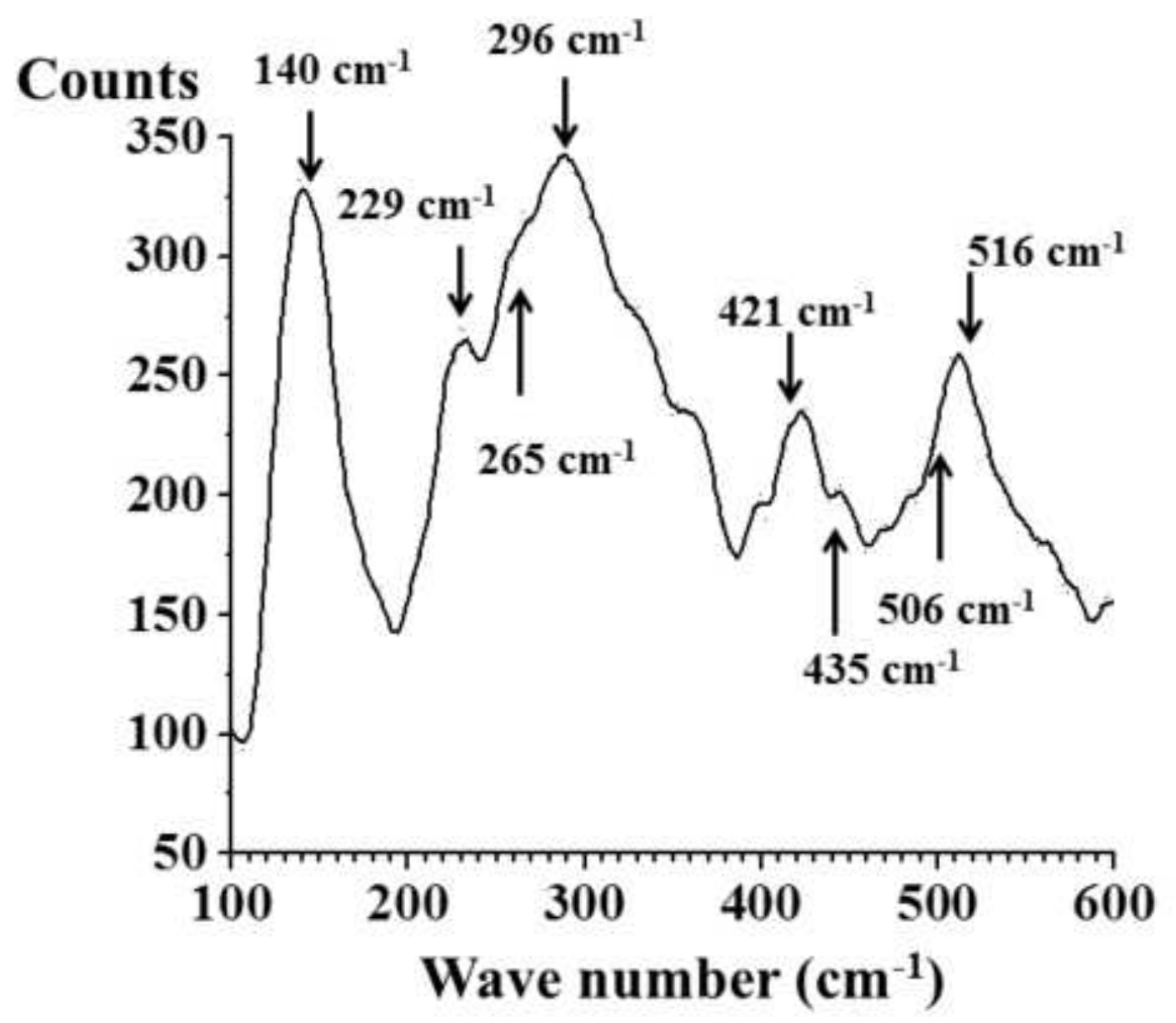




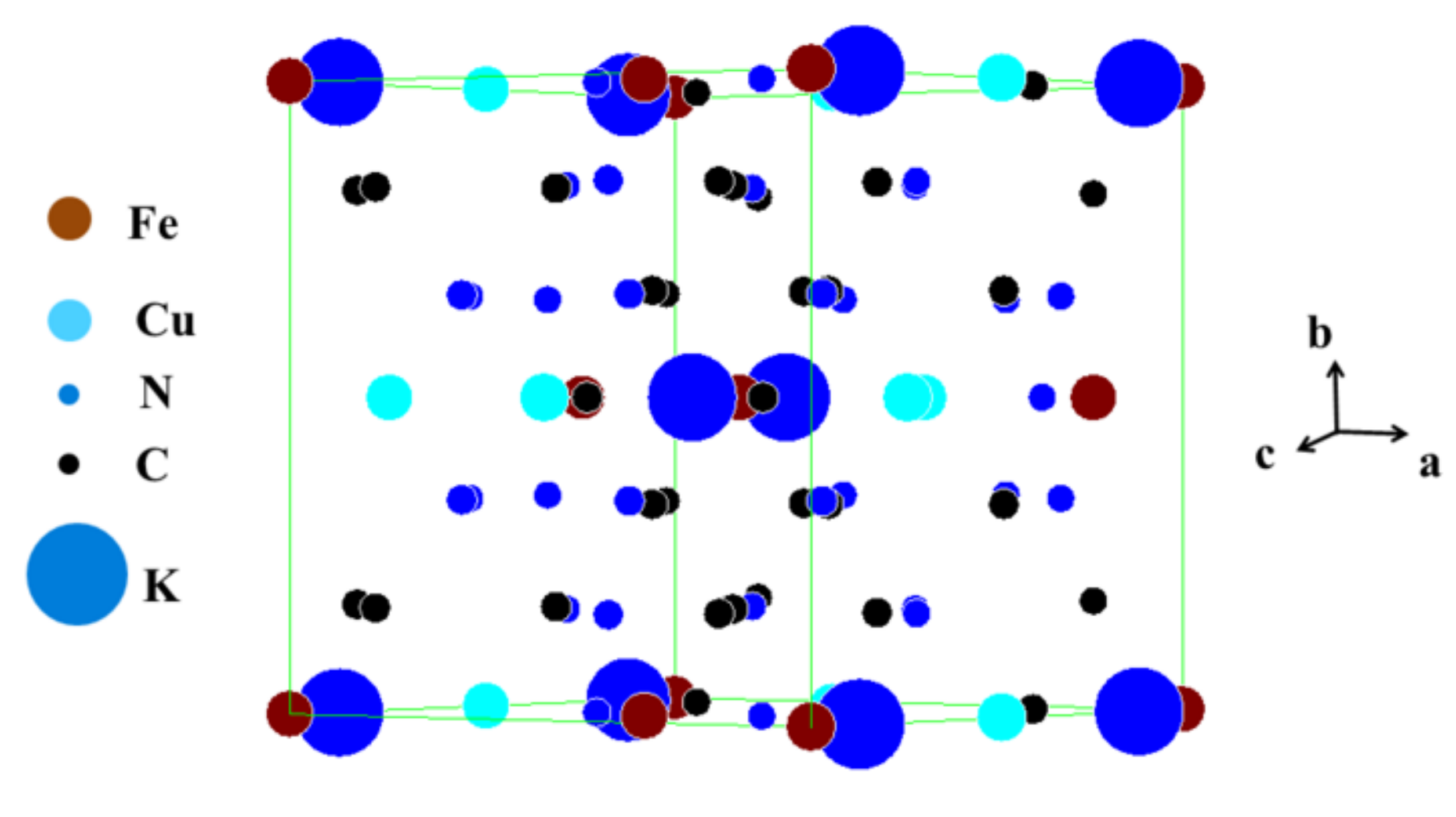

- Fe

$\begin{array}{ll} & \mathbf{C u} \\ - & \mathbf{N} \\ - & \mathbf{C} \\ \mathbf{K}\end{array}$


Table 1. Refined cell parameters and crystallite sizes

\begin{tabular}{|l|l|l|l|l|l|}
\hline Sample & $\boldsymbol{a}(\dot{A})$ & $\boldsymbol{c}(\dot{A})$ & $\boldsymbol{V}\left(\bar{A}^{3}\right)$ & $\boldsymbol{\Phi}(\mathbf{n m})$ & $\boldsymbol{S . G .}$ \\
\hline Cu-PBA & $10.078(2)$ & & $1024.1(2)$ & $30(1)$ & $P m \overline{3} m$ \\
\hline Cu-PBA-I & $9.87(1)$ & $10.52(1)$ & $926.8(3)$ & $25(1)$ & $I \overline{4} m 2$ \\
\hline
\end{tabular}


Table 2. Average elemental composition (standard deviation) for the Cu-PBA-II

\begin{tabular}{|l|l|l|l|}
\hline Sample & $\mathbf{C}_{\mathbf{K}}(\boldsymbol{\sigma})$ & $\mathbf{C}_{\mathrm{Fe}}(\boldsymbol{\sigma})$ & $\mathbf{C}_{\mathrm{Cu}}(\boldsymbol{\sigma})$ \\
\hline Cu-PBA-I & $0.2(1)$ & $1.2(5)$ & $1.5(5)$ \\
\hline
\end{tabular}


Table 3. Low pressure micropore volume $\left(W_{0}\right)$, characteristic energy of adsorption $(E)$ and isosteric heat of adsorption $\left(q_{i s o}\right.$ at $\left.\theta=0.37\right)$.

\begin{tabular}{|l|l|l|l|l|}
\hline Sample & $N_{a}^{0}(\mathrm{mmol} / \mathrm{g})$ & $E(\mathrm{~kJ} / \mathrm{mol})$ & $W_{0}\left(\mathrm{~cm}^{3} / \mathrm{g}\right)$ & $q_{\text {iso }}(0.37) \mathrm{kJ} / \mathrm{mol}$ \\
\hline $\mathrm{Cu}-\mathrm{PBA}$ & $1.62(1)$ & $17(2)$ & $0.078(5)$ & $20(2)$ \\
\hline $\mathrm{Cu}-\mathrm{PBA}-\mathrm{I}$ & $1.84(1)$ & $16(2)$ & $0.089(5)$ & $19(2)$ \\
\hline
\end{tabular}


Table 4. Parameters of the IR peaks related to adsorbed carbon dioxide on Cu-PBA-I.

\begin{tabular}{|l|l|l|l|l|}
\hline Sample & $x_{1}\left[\Delta x_{1}\right]\left(\mathrm{cm}^{-1}\right)$ & $A_{I}(\%)$ & $x_{2}\left[\Delta x_{2}\right]\left(\mathrm{cm}^{-1}\right)$ & $A_{2}(\%)$ \\
\hline Adsorbed $\mathbf{C O}_{2}$ & $2339[17]$ & 60 & $2306[64]$ & 40 \\
\hline
\end{tabular}




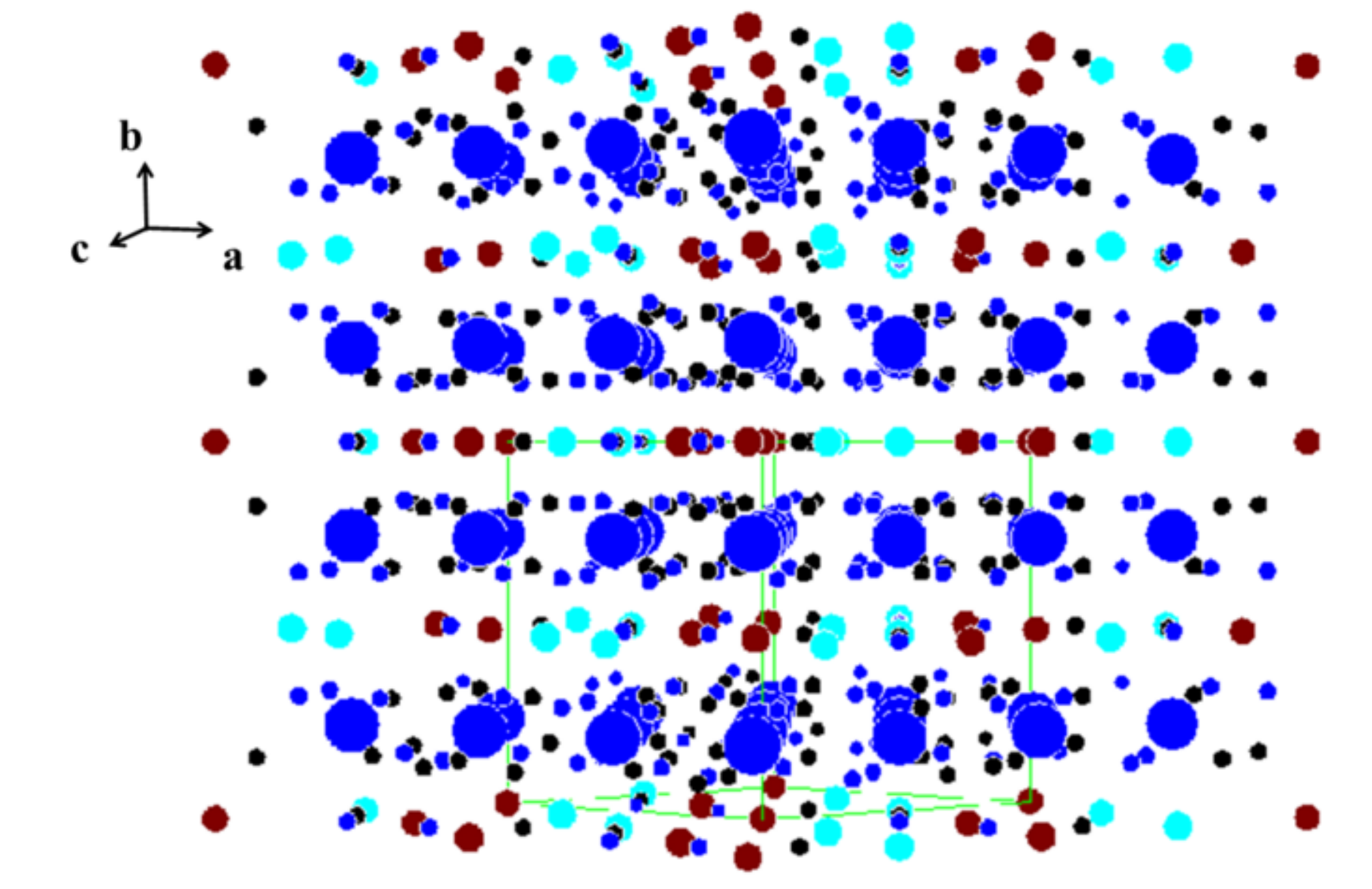

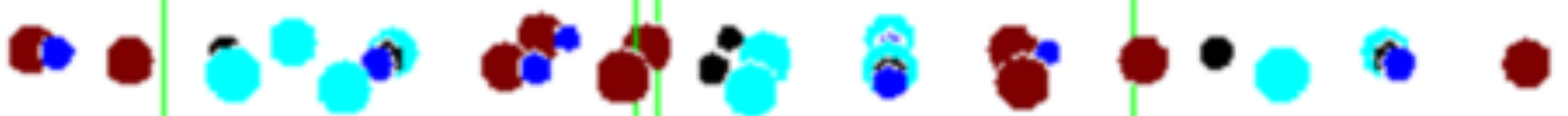
$\rightarrow 20,0.000$

\section{.}
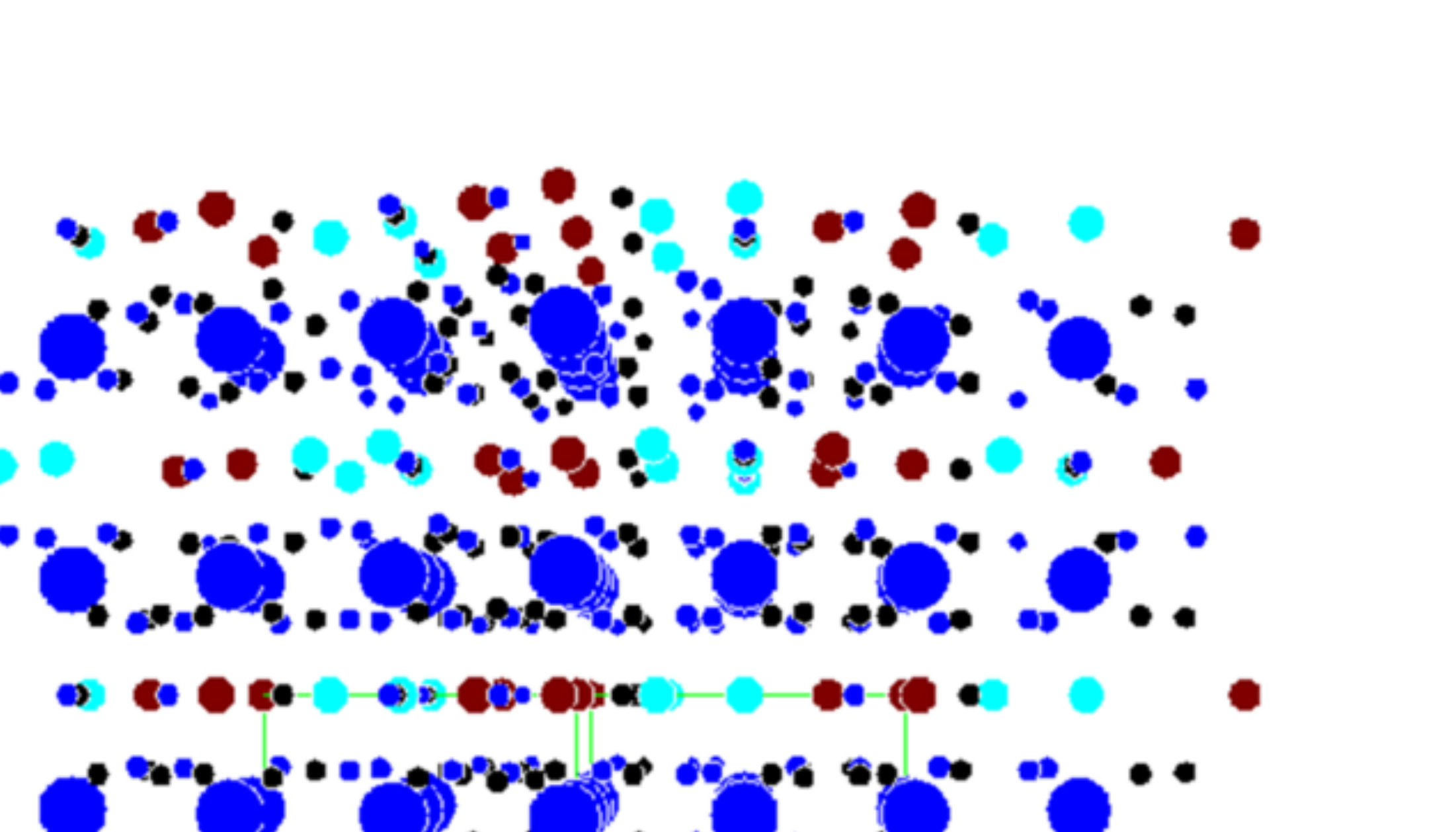

0
- - o cos 80.

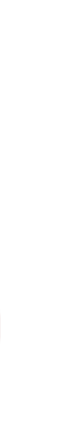
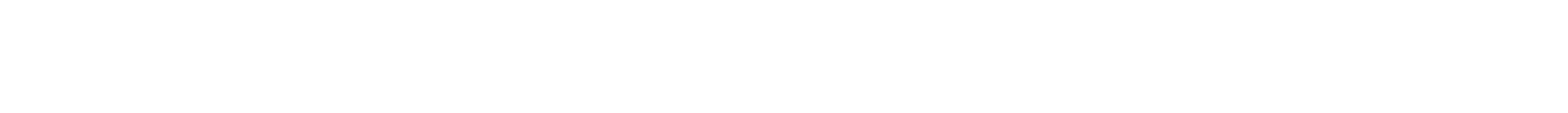